\title{
La movilidad ocupacional de los graduados en las universidades públicas catalanas ${ }^{1}$
}

\author{
Occupational mobility of graduates in public \\ universities in Catalonia
}

DOI http://dx.doi.org/10.1344/REYD2018.17.23480

\author{
Sandra Fachelli \\ Investigadora del GRET (Grup de Recerca sobre Educació i Treball) \\ Departament de Sociologia. Universitat Autònoma de Barcelona. \\ 08193 Bellaterra, España. \\ Email: sandra.fachelli@uab.es
}

\footnotetext{
${ }^{1}$ Esta investigación formó parte del Proyecto ITUNEQMO (CSO2010-19271) financiado por el Ministerio de Ciencia e Innovación. Fue reelaborado en el contexto del Proyecto de investigación "Anàlisi de la situació de partida cap al món laboral dels graduats de la Facultat de Dret i transferència de l'experiència a la Facultat d'Economia i Empresa de la UB i a nivell internacional" (REDICE16-1682), bajo la dirección de Antonia Collado, y se inscribe en el contexto de la Red INCASI, proyecto europeo que recibe financiación del programa de investigación e innovación Horizonte 2020 bajo Marie Skłodowska-Curie GA No 691004, coordinado por Pedro López-Roldán. "Este artículo refleja sólo el punto de vista del autor y la Agencia no es responsable por el uso que se le pudiera dar a la información que contiene".
} 
Resumen: El objetivo de este artículo es dar cuenta del proceso de movilidad ocupacional de una generación concreta de graduados universitarios en el curso académico 2006-2007, ocupados a tiempo completo y entrevistados en 2011 por la Agencia para la Calidad de Sistema Universitario Catalán (AQU). Asimismo, discute la pertinencia de la medición del proceso de movilidad en este colectivo específico y, en particular, se aplica un modelo log-lineal topológico para el análisis de la movilidad relativa. Los resultados obtenidos ponen de manifiesto que la generación de graduados analizada posee un alto grado de equidad en el proceso de inserción laboral, al tiempo que se observada que los modelos teóricos tradicionalmente utilizados para analizar la movilidad relativa global en las sociedades avanzadas no ajustan cuando se aplican a la cohorte bajo análisis. Es por ello que se propone un modelo topológico que dé cuenta de estos perfiles.

Palabras clave: Movilidad ocupacional intergeneracional, movilidad absoluta y relativa, educación superior, modelos topológicos.

Abstract: The objective of this article is to account for the occupational mobility process of a specific generation of university graduates in the academic year 2006-2007, occupied full time jobs and interviewed in 2011 by the Agency for Quality of Catalan University System (AQU). It also discusses the relevance of the measurement of the mobility process in this specific group and, in particular, a topological log-linear model is applied for the analysis of relative mobility. The obtained results show that the generation of graduates analyzed has a high degree of equity in the process of labor insertion, while it was observed that the theoretical models traditionally used to analyze global relative mobility in advanced societies do not adjust when is applied to the cohort under analysis. For that reason, a topological model is proposed in order to accounts for the profiles of these universities graduates.

Key Words: Intergenerational occupational mobility, absolute and relative mobility, Higher Education, topological models.

Fecha de entrada: $26 / 4 / 2017$

Fecha de aceptación: 27/7/2017
REVISTA DE EDUCACIÓN Y DERECHO. EDUCATION AND LAW REVIEW Número 17. Abril 2018 - septiembre 2018 


\section{La movilidad ocupacional de los graduados en las universidades públicas catalanas}

Occupational mobility of graduates in public universities in Catalonia

\section{Introducción}

En este artículo nos proponemos analizar los cambios que se han producido en términos de movilidad ocupacional intergeneracional en un grupo social específico como son los graduados en las universidades públicas catalanas en el curso académico 2006-2007 que han sido encuestados en $2011^{2}$. La idea concreta es realizar la comparación con sus padres en aras de responder las siguientes preguntas:

1) ¿En qué medida los hijos universitarios se diferencian de sus padres en términos de categoría ocupacional (movilidad absoluta)?

2) ¿En qué medida los modelos tradicionales utilizados para analizar la movilidad social relativa son adecuados para analizar este perfil específico de graduados universitarios?

3) En caso que los modelos tradicionales no funcionen ¿cuál sería el patrón que define a este grupo particular de la sociedad catalana?

Luego de una referencia de los principales estudios de movilidad a nivel internacional, mencionaremos algunos estudios existentes en España sobre la temática.

Este estudio se realiza en el contexto de una línea de investigación cuyo objetivo es conocer las relaciones existentes en la compleja interacción entre Educación Superior y ocupación, prestando especial atención al proceso de movilidad intergeneracional.

\footnotetext{
${ }^{2}$ Los egresados de las universidades públicas representan el 74,6\% del total de egresados en Cataluña en el año académico 2009-2010 según los datos de la Generalitat de Catalunya.

http://www.gencat.cat/economia/ur/serveis/estudis_estadistiques/index.html
} 


\section{Antecedentes}

El punto de partida en los análisis de movilidad fue la tesis de Lipset y Zetterberg (1959) que observaron una similitud en las tasas de movilidad en las sociedades occidentales industrializadas. Sin embargo, estudios posteriores mostraron poco apoyo a esa posición (Hauser y Featherman 1977; Erikson et al 1979). Featherman, Jones y Hauser (1975) sugirieron que la variación observada en las tasas de movilidad podría derivarse de las diferencias históricas y culturales en las estructuras ocupacionales, pero no por las diferencias en los intercambios entre ocupaciones. Esta hipótesis, conocida bajo la etiqueta FJH y revisada por Erikson y Goldthrope (1993), conduce a la predicción de que las posibilidades de movilidad relativa son invariantes una vez controladas las variaciones en las distribuciones de origen y destino (Grusky y Hauser 1984: 20-22).

"The Constant Flux" ha sido la obra cuya aparición ha generado una muy prolifera y sistemática producción de estudios de movilidad. La consolidación de un procedimiento estándar para analizar los procesos de cambio en las sociedades desarrolladas, así como un conjunto de técnicas para el análisis de las relaciones entre esos cambios, la ha erigido como el modelo a seguir en este tipo de análisis.

No obstante, las discusiones continúan, pues trabajos posteriores ponen en cuestión el principal hallazgo en términos de invariación en los cambios de las tasas relativas de movilidad. Concretamente Breen et al. (2004) afirman haber encontrado una tendencia general, con una o dos excepciones, hacia el aumento de la fluidez social, ellos realizan el estudio para 11 países europeos entre 1970 y 2000.

En España se ha realizado este tipo de análisis con el fin de constatar la tan mentada conclusión de la permanencia en las posiciones relativas de Erikson y Goldthorpe. Los estudios realizados con la Encuesta Sociodemográfica por Julio Carabaña en 1999 constata este patrón para España. También constata la hipótesis de fluidez constante el trabajo de Echevarría (1999) con la Encuesta de Estructura, Conciencia y Biografía de Clase, lo constata Marqués y Herrera-Usagre (2010) con la Encuesta de Condiciones de Vida, y más recientemente lo constatan Fachelli y López-Roldán (2015). ${ }^{3}$

\footnotetext{
${ }^{3}$ Los estudios internacionales tradicionalmente han utilizado sólo a los varones para analizar la movilidad. El estudio de 2015 utiliza varones y mujeres.
} 
Para el caso concreto de Cataluña, Martínez Celorrio y Marín Saldo (2010), encuentran una sociedad caracterizada por el ascenso social en términos de movilidad absoluta, por el incremento de la movilidad relativa y con una pauta meritocrática de ascenso social donde la educación prevalece frente a la clase social de origen (el estudio incluye a ambos sexos). ${ }^{4}$

En el caso concreto de España, el proceso de expansión educativa se inicia más tarde que en los países de su entorno, pero es más acelerado, lo que hace que las diferencias en las oportunidades educativas de las generaciones jóvenes en relación a las de sus padres, hayan sido muy superiores a las que podemos observar en países europeos para las mismas generaciones (Beduwe y Planas 2003:173-175). Asimismo, podemos afirmar que aunque el nivel de estudios de los jóvenes españoles hoy es análogo a los países de la Unión Europea, las oportunidades de estudiar que tuvieron los padres de los titulados universitarios fue menor que la de sus coetáneos europeos considerados globalmente y, consecuentemente, las distancias entre padres e hijos son mayores (Fachelli y Planas 2011: 1285).

En este sentido hay varios factores que nos llevan a considerar que estaríamos en el primer proceso mencionado por Breen y Jonsson donde la relación origen-educación-destino puede influir en las tasas de fluidez social. Concretamente para Cataluña se constata una pauta de movilidad relativa que reduce la rigidez clasista y también se logra demostrar que la educación ha jugado un rol preponderante en este aumento de la fluidez social así como también que dicho fenómeno ha neutralizado el efecto de clase en aquellos sectores beneficiados por la expansión educativa (Martínez Celorrio y Marín Saldo 2010: 117-158).

Nosotros mismos tuvimos ocasión de constatar en un estudio previo que la educación universitaria constituyó un factor de equidad y de movilidad ocupacional para la generación de graduados en 2004-2005 (Fachelli y Planas, 2011). Aunque sabemos que son varios los elementos que podemos destacar como filtros al acceso, muchos de carácter económico (Albert 1998; Becker 1975; Kodde 1986) y otros asociados en mayor medida a aspectos culturales (Bourdieu y Passeron 1990; Goldthorpe 2007; Merton 1980; Bernstein 1988; Bree y Goldthorpe 1997). Torrents (2012) vinculando estos aspectos logra constatar en el contexto español para el año 2009 que ambos elementos inciden y que el primer factor está asociado a pertenecer a una familia de clase obrera.

\footnotetext{
${ }^{4}$ Nuestro estudio tiene una sola generación de graduados con lo cual no podremos hacer ninguna referencia a este aspecto.
} 
La crisis económica ha afectado tanto a la inserción laboral de los que logran finalizar la universidad, pero aún más importante ha potenciado las tradicionales barreras al acceso a la educación superior. En este sentido es interesante resaltar que casi el 10\% de universitarios del curso 2009-2010 ingresaban a través de vías profesionales y más de la mitad de ellos pertenecía a familias con bajo nivel educativo. Esto contrasta con el $61 \%$ de estudiantes que acceden desde bachillerato que tenían un nivel educativo familiar más elevado (Ustrell 2011: 83-87).

También en investigaciones recientes hemos conocido la relativa "poca exclusión" que ha generado el sistema universitario catalán al constatar que los altos porcentajes de abandono reflejados por algunas estadísticas oficiales (2000-2004) -que los sitúan entre el 25\% y 50\%quedan reducidos al 13,6\% de los estudiantes, si se toma en cuenta los itinerarios de reorientación de carrera o cambio de universidad y el abandono transitorio -reingreso a la universidad- después de un tiempo de no matriculación (Sanchez-Gelabert 2011: 31).

Todos los elementos que se habían observado de aumento de la equidad en el sistema superior de educación que inciden en favorecer la fluidez social seguramente quedarán afectados por la gran crisis que hemos atravesado.

Los datos que exploraremos están atravesados por la primera etapa de la crisis (Navarro y Fachelli, 2017) y no nos permiten analizar la situación con otros grupos de graduados en décadas anteriores, pero en todo caso estamos analizando una generación de titulados que ha tenido tiempo de insertarse antes de que la crisis los afecte profundamente.

\section{Metodología}

AQU encuesta a 11.843 graduados (Anexo 1) y nos ofrece una clasificación ocupacional diferente al conocido esquema de clases de Erikson y Goldthorpe, y es la que utilizamos para este análisis, pues está directamente disponible para los padres y madres de graduados.

En este sentido lo que hemos hecho es homologar esa clasificación para el caso de los hijos e hijas. Para ello hemos seguido el criterio metodológico desarrollado en Planas y Fachelli (2010) que consiste en considerar el máximo nivel ocupacional del padre o de la madre del graduado o graduada y clasificar a los hijos en 5 categorías ocupacionales. ${ }^{5}$

\footnotetext{
${ }^{5}$ 1. Dirección: trabajadores por cuenta ajena que realizan tareas directivas.

2. Técnico Superior: trabajadores por cuenta ajena que no ejercen funciones de dirección, pero que para acceder al trabajo necesitan tener título universitario o que sus funciones requieren formación universitaria. Esta categoría incluye a los Trabajadores por cuenta propia que para realizar el trabajo necesitan tener título universitario o que las funciones requieren formación universitaria.
} 
Para explorar la movilidad ocupacional absoluta y relativa aplicamos la metodología habitual que se describe sucintamente a continuación y que para mayor detalle puede consultarse en Fachelli y López-Roldán (2012). ${ }^{6}$

\subsection{Movilidad absoluta}

Bajo el rótulo de movilidad absoluta puede contabilizarse tanto las personas que tienen una situación de mayor jerarquía o que mejoran con respecto a su origen (movilidad ascendente) como aquellas tienen una posición de menor jerarquía que la de sus padres o que todavía no la han alcanzado (movilidad descendente).

Se denomina reproducción, herencia o inmovilidad al hecho de que padres e hijos tengan la misma posición social, debido a una transmisión de posición ocupacional de padres a hijos o simplemente por coincidir en una situación transitoria en esa posición.

Los porcentajes de salida o outflow hacen referencia al porcentaje de personas de un mismo origen que terminan en cada una de las distintas posiciones de destino (el marginal de cada fila totaliza cien). ${ }^{7}$

\subsection{Movilidad relativa}

Por su parte, en términos de movilidad relativa exploramos los modelos log-lineales que se detallan a continuación.

El modelo saturado o de asociación, que expresa la asociación entre las variables, las frecuencias esperadas coinciden con las frecuencias observadas:

$$
\log \left(\hat{n}_{i j}^{e}\right)=\hat{\lambda}+\hat{\lambda}_{i}^{O}+\hat{\lambda}_{j}^{D}+\hat{\lambda}_{i j}^{O D}
$$

Donde $\hat{\mathrm{n}}_{\mathrm{ij}}^{\mathrm{e}}$ es el efecto esperado de una casilla determinada; $\hat{\lambda}$ es el efecto total que depende del número total de casos; $\hat{\lambda}_{\mathrm{i}}^{0}$ efecto que indica la distribución de los marginales de fila (origen de

3. Calificado: trabajadores por cuenta ajena que no ejercen funciones de dirección, que no les pidieron título universitario o que las funciones no requieren formación universitaria y que el trabajo no es un trabajo "no calificado".

4. Cuenta propia: trabajadores que cumplen esta condición pero que para realizar el trabajo no necesitan tener título universitario o que sus funciones no requieren formación universitaria.

5. No calificado: trabajadores por cuenta ajena que no cumplen las condiciones anteriores y las funciones que desarrollan son "no cualificadas".

${ }^{6}$ Para un análisis más detallado de estas temáticas en versión castellana puede consultarse a Carabaña (1999), Echeverría (1999), Jorrat (1987, 1997, 2005, 2008) y Boado (2011).

${ }^{7}$ A este tipo de movilidad Carabaña (1999) lo denomina movilidad particular, es decir, cuando nos preguntamos por los destinos de las personas que proceden de cada una de las categorías. 
los padres); $\hat{\lambda}_{j}^{\mathrm{D}}$ efecto que indica la distribución de los marginales de columna (destino de los hijos) y $\hat{\lambda}_{\mathrm{ij}}^{\mathrm{OD}}$ efecto de asociación o interacción entre ambas variables.

El modelo de independencia estadística, se reconoce como la hipótesis de la "movilidad perfecta" y supone que no hay relación entre origen y destino. Es la ecuación anterior después de eliminar el parámetro de interacción:

$$
\log \left(\hat{n}_{i j}^{e}\right)=\hat{\lambda}+\hat{\lambda}_{i}^{O}+\hat{\lambda}_{j}^{D}
$$

El modelo de cuasi-independencia o de movilidad cuasi-perfecta (MCP) se basa en la idea propuesta por Goodman (1972) al reconocer la existencia de dos tipos de casos: los que se mueven, para los que hay independencia si todos los destinos son igualmente probables, y los que permanecen estables, localizados en la diagonal (modelo mover-stayer).

El modelo de cuasi-independencia se obtiene especificando una variable que contenga esta estructura de las casillas y solicitando un diseño que se corresponde con el modelo de independencia, y que se concreta en la siguiente ecuación:

$$
\log \left(\hat{n}_{i j}^{e}\right)=\hat{\lambda}+\hat{\lambda}_{i}^{O}+\hat{\lambda}_{j}^{D}+\delta_{i j}
$$

Donde $\delta_{i j}=0$, si $i=j$, y $\delta_{i j}=1$, si $i \neq j$, con $(I-1)(J-1)-I$ grados de libertad.

El modelo de movilidad de esquinas (ME) fue propuesto por Hout en 1983 y considera la existencia de ciertos movimientos especialmente destacados, de corta distancia, que se dan en los extremos superior izquierdo e inferior derechos. Además plantea extender el bloqueo o la cancelación de casillas a la diagonal. El modelo log-lineal de la movilidad de esquinas es un diseño que se corresponde con el modelo de independencia como el anterior con la particularidad de la estructura de la siguiente matriz de diseño.

Matriz de diseño de Hout (1983)

$\begin{array}{lllll}0 & 0 & 1 & 1 & 1 \\ 0 & 0 & 1 & 1 & 1 \\ 1 & 1 & 0 & 1 & 1 \\ 1 & 1 & 1 & 0 & 0 \\ 1 & 1 & 1 & 0 & 0\end{array}$


Por otro lado, uno de los modelos topológicos más reconocido en la literatura es el de Hauser (1979) en el que establece como hipótesis que se puede esperar en los niveles sociales más bajos tengan más rigidez y más herencia que los niveles altos, donde se daría mayor fluidez social. Este modelo se expresa de la forma siguiente:

Matriz de diseño de Hauser (1979)

$\begin{array}{lllll}2 & 4 & 5 & 5 & 5 \\ 3 & 4 & 5 & 5 & 5 \\ 5 & 5 & 5 & 5 & 5 \\ 5 & 5 & 5 & 4 & 4 \\ 5 & 5 & 5 & 4 & 1\end{array}$

\section{Resultados}

\subsection{Movilidad absoluta}

La relación entre la población de titulados universitarios ocupados a tiempo completo y sus padres, se muestra a continuación:

Tabla 1. Distribución de la categoría ocupacional de padres (Origen) e hijos (Destino)

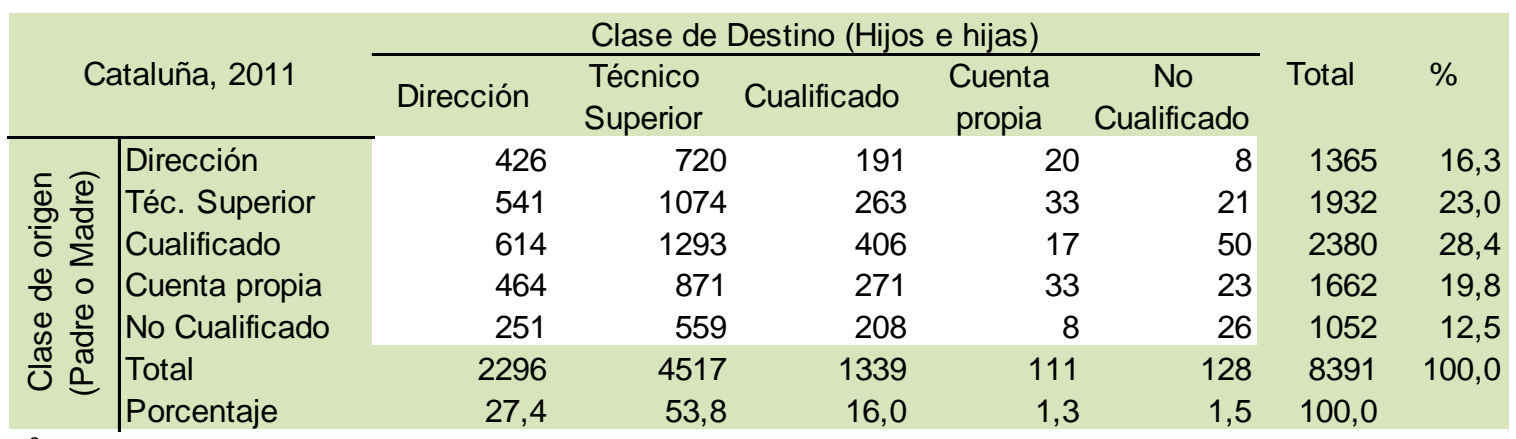

$\chi^{2}=77,386(0,000) ; \mathrm{V}$ de Cramer $=0,048$

Fuente: Fachelli y Planas (2012) sobre la base de AQU 2011

Vemos que la muestra total $\mathrm{n}$ es de 8.391 titulados, los totales marginales de fila reflejan la clase de Origen representada por la máxima categoría ocupacional del padre o la madre y en los totales marginales de columna se representan los valores absolutos de la clase de Destino, expresada por la categoría ocupacional de los titulados universitarios. Cabe destacar que el 97,2\% de los titulados se acumula en tres de las cinco categorías ocupacionales: dirección, técnico superior y cualificado. 
Si bien existe asociación entre origen y destino, el hecho que la V de Cramer sea tan baja, nos está hablando de que los graduados universitarios han logrado una movilidad que se acerca a los niveles de independencia, es decir, que el origen apenas los está condicionando para insertarse en el mercado laboral. Nótese que un 4\% de asociación es un valor muy pequeño.

Tabla 2. Padres e hijos según categorías ocupacionales

\begin{tabular}{lccc} 
Cataluña, 2011 & Padres (1) & Hijos (2) & $\begin{array}{c}\text { Diferencia } \\
(1)-(2)\end{array}$ \\
\hline Dirección & 16,3 & 27,4 & $-11,1$ \\
Téc. Superior & 23,0 & 53,8 & $-30,8$ \\
Cualificado & 28,4 & 16,0 & 12,4 \\
Cuenta propia & 19,8 & 1,3 & 18,5 \\
No Cualificado & 12,5 & 1,5 & 11,0 \\
Total & 100,0 & 100,0 & 0,0
\end{tabular}

Fuente: Elaboración propia

Podemos destacar que los padres que realizan trabajos por cuenta propia y no calificado llegan al $32 \%$, en cambio sus hijos no superan el $2,8 \%$ en estas categorías.

La movilidad absoluta total es del $76 \%$, compuesta por el movimiento ascendente (60\%) y el descendente (16\%). Las posiciones similares entre padres e hijos es el 23,4\%. La descomposición entre hijas e hijos da guarismos semejantes, aunque las mujeres muestran un leve aumento de la movilidad ascendente.

Tabla 3. Tasas de Movilidad absoluta por sexo

\begin{tabular}{|l|c|c|c|}
\hline \multicolumn{1}{|c|}{ Movilidad } & Todos & Mujeres & Varones \\
\hline Total & 76,6 & 77,6 & 75,2 \\
\hline Ascendente & 60,5 & 61,9 & 58,7 \\
\hline Descendente & 16,0 & 15,7 & 16,5 \\
\hline \multicolumn{4}{|c|}{} \\
\hline Inmovilidad & 23,4 & 22,4 & 24,8 \\
\hline
\end{tabular}

Fuente: Elaboración propia

Al observar las distintas tareas realizadas por los titulados según origen social es interesante advertir que la influencia del origen de los padres sobre la ocupación de los hijos no es importante, pues los titulados están relativamente representados en forma similar provengan del origen que provengan 
Tabla 4. Distribución de la categoría de los hijos según origen social

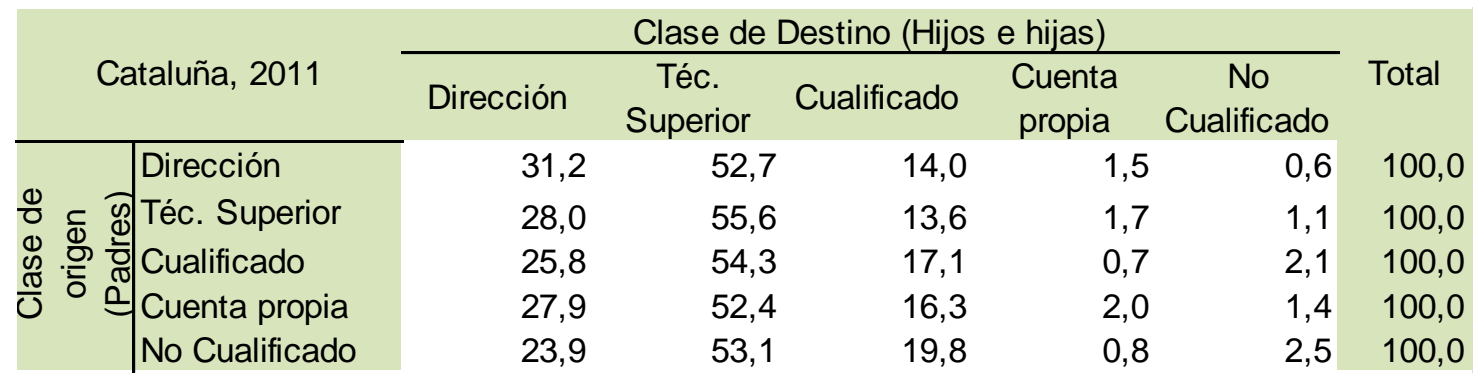

Fuente: Fachelli y Planas (2012) sobre la base de AQU 2011

La excepción la conforman las categorías extremas de los hijos directores, pues provienen de padres directores un $31 \%$ mientras que lo que provienen de padres no cualificados son un $24 \%$. En el caso de la división por sexo la misma conclusión se mantiene en términos de la relativa equidad, dado que lleguen a donde lleguen, en los graduados se observa una distribución similar por origen. Sin embargo, aparece aquí la diferenciación entre sexos, los varones predominan en posiciones más altas y las mujeres en las más bajas.

Tabla 5. Distribución de la categoría de las hijas e hijos según origen social

\begin{tabular}{|c|c|c|c|c|c|c|c|c|c|c|c|c|}
\hline \multirow{2}{*}{$\begin{array}{l}\text { Clase de origen } \\
\text { (Padre o Madre) }\end{array}$} & \multicolumn{6}{|c|}{ Hijas ocupadas } & \multicolumn{6}{|c|}{ Hijos ocupados } \\
\hline & 1 & 2 & 3 & 4 & 5 & $\overline{\text { Total! }}$ & 1 & 2 & 3 & 4 & 5 & Total \\
\hline Dirección & 26,4 & 59,1 & 12,9 & 0,9 & 0,7 & 100 & 36,9 & 45,2 & 15,3 & 2,1 & 0,5 & 100 \\
\hline Téc. Superior & 24,9 & 59,0 & 14,0 & 1,2 & 1,0 & 1001 & 32,2 & 51,1 & 13,1 & 2,4 & 1,2 & 100 \\
\hline Cualificado & 21,1 & 60,5 & 16,1 & 0,3 & 2,0 & 1001 & 32,8 & 45,0 & 18,6 & 1,4 & 2,2 & 100 \\
\hline Cuenta propia & 25,1 & 57,2 & 15,1 & 1,1 & 1,5 & 100 & 32,2 & 45,2 & 18,1 & 3,3 & 1,2 & 100 \\
\hline No Cualificado & 20,7 & 57,1 & 19,1 & 0,6 & 2,5 & 100 & 29,0 & 46,8 & 20,8 & 1,0 & 2,5 & 100 \\
\hline
\end{tabular}

Fuente: Fachelli y Planas (2012) sobre la base de AQU 2011

Los elementos analizados hasta el momento nos permiten concluir que los graduados universitarios tienen un alto nivel de movilidad ocupacional frente a sus padres y que, consecuentemente, la universidad ha brindado recursos para dicho posicionamiento.

\subsection{Movilidad relativa}

Ahora pasamos a analizar las relaciones entre las posiciones entre padres e hijos en términos relativos. Es decir, dejamos de lado los marginales de fila y columna de la tabla de movilidad y nos detenemos en la mayor o menor propensión o probabilidad existente a pasar de determinados orígenes a determinados destinos proviniendo de un origen determinado. 
Observamos entonces, en términos de movilidad relativa, que los modelos tradicionalmente aplicados no ajustan.

Tabla 6. Movilidad relativa, aplicación de modelos log-lineales

\begin{tabular}{|c|c|c|c|c|c|c|}
\hline Modelo & $\mathrm{L}^{2}$ & $\begin{array}{l}\text { Grados } \\
\text { de } \\
\text { libertad }\end{array}$ & Sig. & BIC & Pseudo $\mathrm{R}^{2}$ & $\begin{array}{l}\text { Índice de } \\
\text { disimilitud }\end{array}$ \\
\hline \multicolumn{7}{|l|}{ Origen y Destino } \\
\hline Saturado [O D] & 0,000 & 0 & 1,000 & 0,00 & $100,0 \%$ & $0,00 \%$ \\
\hline Independencia [O] [D] & 79,150 & 16 & 0,000 & $-65,41$ & $0,0 \%$ & $2,81 \%$ \\
\hline Cuasi-independencia (Goodman) & 52,630 & 11 & 0,000 & $-46,75$ & $33,5 \%$ & $2,61 \%$ \\
\hline Esquinas (Hout) & 35,932 & 7 & 0,000 & $-27,31$ & $54,6 \%$ & $2,01 \%$ \\
\hline Topológico (Hauser) & 45,653 & 12 & 0,000 & $-62,77$ & $42,3 \%$ & $1,44 \%$ \\
\hline
\end{tabular}

$L^{2}$ razón de máxima verosimilitud: valor del estadístico de bondad de ajuste.

BIC: Bayesian Information Criterion. Evalúa la relación en verosimilitud entre cada modelo y el saturado.

Pseudo $\mathrm{R}^{2}$ : También llamado coeficiente de determinación múltiple y simbolizado como $\mathrm{rG}^{2}$, mide qué

Índice de disimilitud: proporción de casos que deberían reclasificarse para llegar a la situación de

Fuente: Elaboración propia

En términos generales, el modelo de independencia no refleja un nivel de desconexión entre origen y destino. El Modelo de Goodman no constata la hipótesis que los movimientos entre categorías adyacentes sean más fáciles. El modelo de las esquinas de Hout tampoco constata los movimientos de corta distancia en los extremos (alta y baja movilidad). Por su parte el modelo topológico de Hauser tampoco ajusta, mostrando que no puede constatarse la tesis sobre que los niveles sociales más bajos sean más rígidos y muestren mayor herencia, frente a los niveles más altos que suelen tener mayor fluidez social.

Evidentemente, estamos ante un colectivo muy particular, se trata de un grupo de personas que contribuye con un grado muy alto de movilidad absoluta al conjunto de la sociedad. Con lo cual es pertinente concluir que sus patrones de comportamiento son totalmente distintos de los modelos clásicos tradicionalmente analizados para observar la movilidad relativa global.

Entonces, es pertinente preguntarse ¿qué modelo da cuenta de estas particularidades? En el apartado siguiente intentaremos dar respuesta a este interrogante.

\subsection{Modelo topológico propuesto}

Hauser $(1978 ; 1979)$ define los modelos topológicos como aquellos donde se pueden agrupar las casillas de la tabla en un número $\mathrm{K}$ de subconjuntos, mutuamente exclusivos y exhaustivos, 
que se caracterizan por compartir un parámetro común de interacción, que refleja la densidad de la movilidad o inmovilidad de cada una en relación al resto.

Esta definición la podemos leer también en otros autores. Hout (1986: 37-38) la sintetiza afirmando que en los modelos topológicos todas las celdas a un mismo nivel comparten parámetros comunes de interacción. En palabras de Echeverría Zabalza (1999: 649) los modelos topológicos o modelos "de niveles" son modelos logarítmico lineales que se basan en el supuesto de que determinados grupos de casillas de una tabla de movilidad tienen un mismo nivel de interacción entre las variables. Para Boado (2010: 86) un modelo topológico básicamente pondera las estimaciones para las celdas a partir de la explicitación de un mapa teórico de la distribución de los casos. Es una hipótesis sobre la densidad de casos en las celdas. Siguiendo las aportaciones generales de Hauser hemos explorado diversas alternativas con el fin de encontrar los patrones o rasgos principales que caracterizan al grupo de graduados universitarios.

Ahora bien, atendiendo al problema advertido por Erikson y Goldthorpe (1993: 122) sobre emplear estos modelos empíricamente, es decir, buscar el ajuste de los datos en lugar de ser guiados por una racionalidad teórica, tomamos como referencia teórica el proceso de investigación que siguieron estos autores para analizar la movilidad social de Inglaterra y Francia.

Ellos consideran que las pautas de fluidez de las modernas sociedades industriales conforman un espacio de diferentes dimensiones y en ese sentido construyen diferentes matrices de movilidad, o en otros términos, diferentes modelos topológicos para captar esas diferencias.

$\mathrm{Su}$ modelo tiene en cuenta tres tipos de consideraciones teóricas dado que las posiciones sociales, definidas dentro de la estructura de clases sociales, deben ser ejercidas como una influencia distintiva en las propensiones de movilidad y son agrupadas en tres concepciones diferentes (Goldthorpe 1993: 122-123):

- la deseabilidad relativa de las diferentes posiciones de clase, consideradas como destinos (se trata de la primera categorización de Goldthorpe y Hope de 1974, donde utilizan una escala de deseabilidad para construirla) $)^{8 ;}$

\footnotetext{
${ }^{8}$ En una investigación sobre movilidad social dirigida por Glass, donde Goldthorpe y Hope (en 1974) construyeron una escalas de prestigio ocupacional para el Oxford Mobility Study, en la cual introdujeron una dimensión nueva ya que hicieron que los entrevistados jueces ordenaran un grupo de 20 ocupaciones en términos de su "deseabilidad social percibida" (Atria 2004: 22) El modelo desarrollado por Golthorpe y Hope (1974) tiene en cuenta la situación de trabajo y la situación de mercado, combinadas con la situación de empleo, que distingue las siguientes categorías:
} 
- las ventajas relativas proporcionadas a los individuos por los diferentes orígenes de clase, en forma de recursos materiales, culturales y sociales;

- las barreras relativas a las que deben hacer frente los individuos para acceder a las diferentes posiciones de clase, las cuales pueden ser consideradas como requisitos o exigencias de capital, cualificaciones, influencias, etc.

Nosotros utilizamos como guía estos conceptos para indagar las relaciones existentes entre los graduados. Así, la matriz topológica que hemos diseñado para describir las relaciones entre las diferentes casillas de la tabla de movilidad de los graduados universitarios se presenta a continuación:

$\begin{array}{lllll}7 & 8 & 5 & 3 & 1 \\ 5 & 7 & 4 & 3 & 1 \\ 4 & 5 & 4 & 2 & 1 \\ 5 & 6 & 4 & 3 & 1 \\ 4 & 5 & 4 & 2 & 1\end{array}$

Barreras relativas (Matrices 1,2 y 3 ) Deseabilidad relativa (Matrices 4, 5 y 6 ) Ventajas relativas (Matrices 7 y 8 )

Este modelo describe 8 comportamientos del colectivo de graduados que se expresan en las siguientes matrices de diseño:

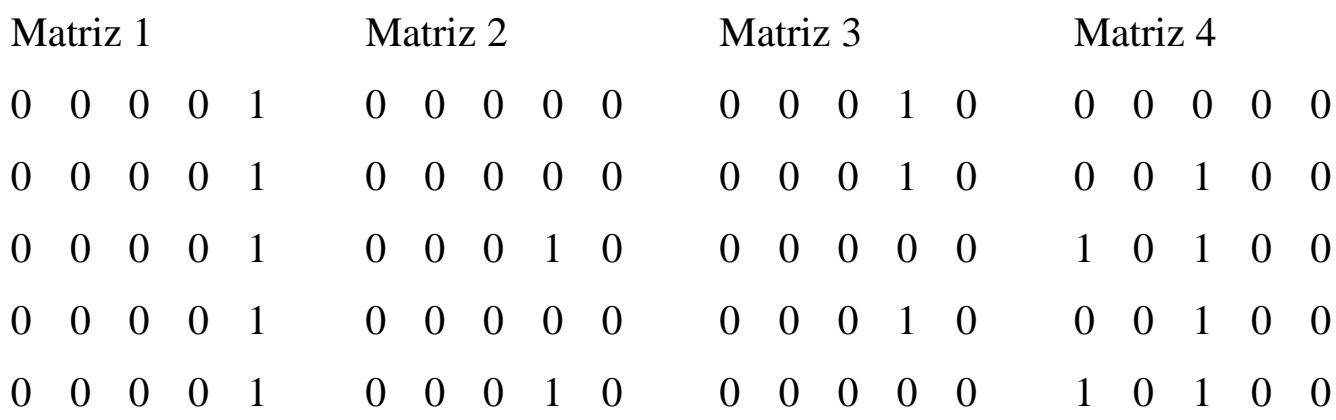

Matriz 5

$\begin{array}{lllllll}0 & 0 & 1 & 0 & 0\end{array}$

$1 \quad 0 \quad 0 \quad 000$

$\begin{array}{lllll}0 & 1 & 0 & 0 & 0\end{array}$

$1 \quad 0 \quad 0 \quad 000$
Matriz 6

$\begin{array}{lllll}0 & 0 & 0 & 0 & 0\end{array}$

$\begin{array}{lllll}0 & 0 & 0 & 0 & 0\end{array}$

$\begin{array}{lllll}0 & 0 & 0 & 0 & 0\end{array}$

$\begin{array}{llllllll}0 & 1 & 0 & 0 & 0\end{array}$
Matriz 7

$1 \quad 0 \quad 0000$

$\begin{array}{lllll}0 & 1 & 0 & 0 & 0\end{array}$

$\begin{array}{lllll}0 & 0 & 0 & 0 & 0\end{array}$

$\begin{array}{lllll}0 & 0 & 0 & 0 & 0\end{array}$

\section{Matriz 8}

$\begin{array}{lllll}0 & 1 & 0 & 0 & 0\end{array}$

$\begin{array}{lllll}0 & 0 & 0 & 0 & 0\end{array}$

$\begin{array}{llllll}0 & 0 & 0 & 0 & 0\end{array}$

$\begin{array}{lllll}0 & 0 & 0 & 0 & 0\end{array}$

1. Por cuenta propia, con más de 25 empleados.

2. Por cuenta propia, con menos de 25 empleados.

3. Por cuenta propia, sin empleados.

4. Directivos de empresas con más de 25 subordinados.

5. Directivos de empresas con menos de 25 subordinados.

6. Capataces y supervisores.

7. Empleados 
FACHELLI, Sandra. La movilidad ocupacional de los graduados en las universidades públicas catalanas
$\begin{array}{lllll}0 & 1 & 0 & 0 & 0\end{array}$
$\begin{array}{llllll}0 & 0 & 0 & 0 & 0\end{array}$
$\begin{array}{lllll}0 & 0 & 0 & 0 & 0\end{array}$
$\begin{array}{llllll}0 & 0 & 0 & 0 & 0\end{array}$

La tabla 7 muestra la significación estadística de nuestro modelo topológico para entender las relaciones de movilidad entre los graduados universitarios y sus padres. Al aplicar el análisis log-lineal vemos que el modelo se ajusta a los datos y nos permite validarlo. El valor del BIC como del Pseudo $\mathrm{R}^{2}$ ponen de manifiesto que es el mejor modelo posible cuando se lo compara con los analizados anteriormente.

Tabla 7. Modelo topológico aplicado a los titulados universitarios

\begin{tabular}{|l|c|c|c|c|c|c|}
\hline Modelo & $\mathbf{L}^{2}$ & $\begin{array}{c}\text { Grados } \\
\text { de } \\
\text { libertad }\end{array}$ & Sig. & BIC & Pseudo $^{2}$ & $\begin{array}{c}\text { Índice de } \\
\text { disimilitud }\end{array}$ \\
\hline Topológico & 19,166 & 11 & 0,058 & $-80,22$ & $75,8 \%$ & $1,47 \%$ \\
\hline
\end{tabular}

Fuente: elaboración propia

Estos comportamientos pueden ser sintetizados de la siguiente manera:

a) Bajo el concepto de titulados con barreras relativas para acceder a posiciones ocupacionales, hemos englobado tres grupos cada uno con un perfil diferente pero que en general se caracterizan por no haber rentabilizado aún la educación superior en términos de movilidad (matrices 1, 2 y 3 )

b) En términos de deseabilidad relativa de alcanzar ciertas posiciones, identificamos a dos grandes grupos de titulados, ambos sin ventaja de origen, esto es, que la posición de los padres no juega a favor de alcanzar rápidamente una alta posición ocupacional, sino que alcanzan dichas posiciones por mérito propio (educación superior). Estos grupos son aquellos titulados que logran rentabilizar la educación (matrices 5 y 6 ) y aquellos que están en camino a lograrlo pero que mayormente desempeñan todavía ocupaciones calificadas (matriz 4).

c) Finalmente, identificamos dos grupos con ventajas relativas, es decir, donde el origen del que provienen facilita un posicionamiento en los mejores puestos laborales (matrices 7 y 8$)$

Seguidamente destacamos las características de cada matriz con el fin de realizar una comparación entre cada grupo y el resto de los graduados, tomando en cuenta un conjunto de variables vinculadas con la experiencia del titulado durante su carrera y su último trabajo. 
Para llevar adelante este análisis se utilizó un procedimiento donde se caracteriza cada uno de los grupos con variables que tienen una ventaja relativa más importante y significativa dentro del grupo y que los distingue del resto de los graduados. ${ }^{9}$

De esta manera, de cada grupo sólo se destacarán aquellos elementos que los distingan del valor promedio del conjunto de los graduados.

Por tanto, se presentan los resultados, por cada matriz que describe las principales características, ordenadas según un test de significación estadístico que valora la importancia de aquellas categorías que más contribuyen a caracterizar cada uno de los grupos. El conjunto seleccionado de variables para hacer este análisis, los resultados promedio y la desagregación por cada matriz se presentan en el anexo 2.

Matrices 1, 2 y 3: Titulados que aún no han rentabilizado la educación superior en términos de movilidad (titulados con barreras relativas a la movilidad):

Matriz 1: Se trata de un conjunto reducido de titulados (128 que representan el 1,5\% de la muestra) que trabaja en ocupaciones no calificadas donde no se les ha requerido el título, en mayor medida en sectores del comercio, transporte y en menor proporción en servicios públicos. Este grupo tiene como promedio del índice de calidad laboral ${ }^{10}$ (que varía entre $0 \mathrm{y}$ 100) un valor de 32,2, mientras la media de los titulados alcanza el 66,7. Las áreas de estudio de donde provienen son Ciencias Sociales (52\%) y Humanidades (30\%), en general han realizado una licenciatura y se destaca el nivel primario o sin estudios de los padres. Son titulados que durante la carrera han trabajado a tiempo completo en un trabajo no relacionado, y hay dos grupos diferenciados en cuanto a la antigüedad laboral de trabajo en el momento de la encuesta (1er trimestre 2011): muchos de ellos, hacía menos de un año que estaban ocupados en esa tarea, y otros entre 5 y 10 años.

Matriz 2: Se trata de un número especialmente reducido de titulados (25), que trabajan por cuenta propia y declaran no necesitar su titulación. Son en mayor medida hombres y se destacan los que tienen entre 31 y 40 años de edad. El nivel educativo de los padres es primario o sin estudios.

Matriz 3: Son 86 titulados, mayormente con padres con educación media/alta, que trabajan por cuenta propia y que declaran no necesitar su titulación para desarrollar esa actividad. El índice

\footnotetext{
${ }^{9}$ Se utilizó el procedimiento DEMOD (Descripción de Modalidades) del programa SPAD (Système Portable pour l'Analyse de Données), Morineau (1984).

${ }^{10}$ Índice desarrollado por Corominas et al. (2007).
} 
de calidad ocupacional es 56,7, están empleados en las ramas de comercio, transporte, hotelería, Servicios empresariales y en menor medida Tecnología de la información y comunicación (TIC's). Se destacan los hombres de entre 31 y 40 años, que hace tiempo desarrollan el trabajo actual (un grupo entre 5 y 10 años y otro más de 11 años).

Tabla 8. Peso de cada titulación en las Matrices 1, 2 y 3 (selección de las que son más importantes)

\begin{tabular}{|c|c|c|c|c|c|}
\hline Matriz 1 & $\%$ & Matriz 2 & $\%$ & Matriz 3 & $\%$ \\
\hline Llicenciatura en Història & 8,6 & Enginyeria Tècnica Industrial (Electricitat) & 12,0 & Diplomatura en Ciències Empresarials & 12,8 \\
\hline Diplomatura en Ciències Empresarials & 6,3 & Belles Arts & 8,0 & $\begin{array}{l}\text { Enginyeria Tècnica en Informàtica de } \\
\text { Gestió }\end{array}$ & 8,1 \\
\hline Diplomatura en Relacions Laborals & 6,3 & Diplomatura en Ciències Empresarials & 8,0 & Enginyeria en Informàtica & 7,0 \\
\hline Llicenciatura en Filosofia & 4,7 & Diplomatura en Relacions Laborals & 8,0 & Llicenciatura en Economia & 4,7 \\
\hline Llicenciatura en Ciències del Treball & 3,9 & Llicenciatura en Ciències del Treball & 8,0 & Llicenciatura en Historia de l'Art & 4,7 \\
\hline Llicenciatura en Geografia & 3,9 & Arquitectura & 4,0 & Enginyeria Agronòmica & 3,5 \\
\hline Llicenciatura en Historia de l'Art & 3,9 & Criminologia & 4,0 & Enginyeria de Telecomunicacions & 3,5 \\
\hline $\begin{array}{l}\text { Diplomatura en Gestió i Administració } \\
\text { Pública }\end{array}$ & 3,1 & & & $\begin{array}{l}\text { Llicenciat en Publicitat i Relacions } \\
\text { Públiques }\end{array}$ & 3,5 \\
\hline Llicenciat en Pedagogia & 3,1 & & & $\begin{array}{l}\text { Llicenciatura en Administració i Direcció } \\
\text { d'Empreses }\end{array}$ & 3,5 \\
\hline $\begin{array}{l}\text { Llicenciat en Sociologia } \\
\text { Llicenciatura en Biologia }\end{array}$ & 3,1 & & & & \\
\hline
\end{tabular}

Fuente: elaboración propia sobre la base de AQU, 2011

Matrices 4, 5 y 6: Titulados sin ventaja de origen. La gran mayoría ha rentabilizado la educación superior (titulados con deseabilidad relativa de movilidad)

Matriz 4: Titulados mayormente calificados, sin ventaja de origen. Se trata de 2013 titulados (24\%), cuyos padres tienen bajos niveles educativos, mayores de 31 años, con muchos años de antigüedad en el trabajo actual. En términos relativos se destacan los hombres y están sobrerrepresentados los graduados de la UPC (el 19\% del total de graduados pertenece a este grupo). Mientras estudiaron trabajaron a tiempo completo en una actividad relacionada con el estudio. Se desempeñan en general en el ámbito privado, en ramas de la Industria, agricultura y pesca, Finanzas, Comercio, transporte, hotelería, Servicios públicos y TIC's. El índice promedio de calidad laboral es de 59.

Matriz 5: Se trata de 3048 personas (36,3\%) con una ocupación donde realizan funciones propias de su nivel de estudios, con un índice de calidad ocupacional superior al promedio 69,1, que mientras estudiaron trabajaron a tiempo completo en una actividad relacionada con el estudio, en mayor medida diplomaturas y en menor medida ingeniería. Se destaca una antigüedad laboral de entre 5 y 10 años. Se destacan también los que poseen entre 31 y 40 años y la rama de la actividad está en mayor medida ligada a Finanzas y TIC's. Sus padres tienen bajos niveles educativos. 
Matriz 6: Son 871 personas y representan el 10,4\% del total, que tienen una alta movilidad sin ventaja de origen. Este es el grupo que con mayor fuerza expresa la importante contribución de las universidades de fuera del ámbito metropolitano al proceso de movilidad ocupacional ascendente, pues se trata de titulados que mayormente estudiaron y trabajan en Lleida, Girona y Tarragona, que han estudiado mayormente diplomaturas y que se han insertado en Educación, Sanidad y atención social. Tienen un promedio de 4 años de antigüedad en sus trabajos, en los cuales se requirió titulación específica para acceder, a puestos con una calidad laboral promedio del 70,6, que supera la media de todos los titulados. Se destacan las mujeres con padres que poseen bajos niveles educativos.

Tabla 9. Peso de cada titulación en las Matrices 4, 5 y 6 (selección de las que son más importantes)

\begin{tabular}{|c|c|c|c|c|c|}
\hline Matriz 4 & $\%$ & Matriz 5 & $\%$ & Matriz 6 & $\%$ \\
\hline Diplomatura en Ciències Empresarials & 7,3 & Diplomatura en Ciències Empresarials & 4,4 & Mestre (Educació Infantil) & 6,3 \\
\hline $\begin{array}{l}\text { Llicenciatura en Administració i Direcció } \\
\text { d'Empreses }\end{array}$ & 4,7 & $\begin{array}{l}\text { Llicenciatura en Administració i Direcció } \\
\text { d'Empreses }\end{array}$ & 4,0 & Diplomatura en Ciències Empresarials & 4,0 \\
\hline Diplomatura en Relacions Laborals & 4,6 & Mestre (Educació Infantil) & 3,5 & $\begin{array}{l}\text { Llicenciatura en Administració i Direcció } \\
\text { d'Empreses }\end{array}$ & 3,9 \\
\hline Llicenciatura en Dret & 3,5 & Llicenciatura en Dret & 3,3 & Llicenciat en Medicina & 3,8 \\
\hline $\begin{array}{l}\text { Enginyeria Tècnica en Informàtica de } \\
\text { Gestió }\end{array}$ & 2,9 & Enginyeria en Informàtica & 3,1 & Mestre (Educació Primària) & 3,7 \\
\hline Enginyeria en Informàtica & 2,8 & Diplomatura en Infermeria & 3,0 & Diplomatura en Infermeria & 3,3 \\
\hline $\begin{array}{l}\text { Enginyeria Tècnica en Informàtica de } \\
\text { Sistemes }\end{array}$ & 2,7 & Llicenciatura en Economia & 2,9 & Llicenciatura en Dret & 3,2 \\
\hline Llicenciatura en Economia & 2,6 & Mestre (Educació Primària) & 2,8 & Mestre (Llengua Estrangera) & 3,1 \\
\hline Criminologia & 2,5 & Mestre (Educació Física) & 2,6 & $\begin{array}{l}\text { Enginyeria Tècnica en Informàtica de } \\
\text { Gestió }\end{array}$ & 2,5 \\
\hline Llicenciat en Psicologia & 2,5 & Diplomatura en Relacions Laborals & 2,5 & Llicenciat en Psicologia & 2,4 \\
\hline Llicenciatura en Història & 2,0 & Llicenciat en Medicina & 2,5 & Mestre (Educació Física) & 2,4 \\
\hline $\begin{array}{l}\text { Enginyeria Tècnica Industrial (Electrònica } \\
\text { Industrial) }\end{array}$ & 1,9 & $\begin{array}{l}\text { Enginyeria Tècnica en Informàtica de } \\
\text { Sistemes }\end{array}$ & 2,3 & Mestre (Educació Musical) & 2,4 \\
\hline $\begin{array}{l}\text { Enginyeria Tècnica Industrial (Química } \\
\text { Industrial)) }\end{array}$ & 1,9 & Mestre (Educació Especial) & 2,2 & Llicenciatura en Química & 2,3 \\
\hline Enginyeria Tècnica Industrial (Mecànica) & 1,8 & Diplomatura en Educació Social & 1,9 & Enginyeria Tècnica Industrial (Mecànica) & 2,2 \\
\hline Llicenciat en Pedagogia & 1,8 & Llicenciat en Psicologia & 1,7 & Diplomatura en Relacions Laborals & 2,1 \\
\hline Llicenciatura en Química & 1,8 & Enginyeria Tècnica Industrial (Mecànica) & 1,6 & $\begin{array}{l}\text { Enginyeria Tècnica en Informàtica de } \\
\text { Sistemes }\end{array}$ & 2,1 \\
\hline Enginyeria de Telecomunicacions & 1,7 & $\begin{array}{l}\text { Enginyeria Tècnica en Informàtica de } \\
\text { Gestió }\end{array}$ & 1,6 & Llicenciatura en Psicopedagogia & 2,1 \\
\hline \multirow[t]{2}{*}{ Llicenciatura en Ciències del Treball } & 1,7 & Enginyeria Industrial & 1,6 & & \\
\hline & & $\begin{array}{l}\text { Enginyeria de Telecomunicacions } \\
\text { Mestre (Llengua Estrangera) }\end{array}$ & $\begin{array}{l}1,5 \\
1,4\end{array}$ & & \\
\hline
\end{tabular}

Fuente: elaboración propia sobre la base de AQU, 2011

Matriz 7 y Matriz 8: Titulados con alta ventaja de origen (titulados con ventajas relativas de movilidad)

Matriz 7: Reproducción con ventaja de origen. Se trata de 1500 titulados que representan el 17,9\% del total que tienen uno o dos padres con el máximo nivel educativo. Son jóvenes (23 a 25 años) en mayor medida hombres, en términos relativos hay mayor presencia de graduados en la UPC y en la Pompeu Fabra, trabajan en el sector privado en puestos donde se les ha exigido la titulación específica, se destacan las titulaciones de Ingeniería, Medicina y 
Veterinaria, tienen alto nivel de calidad en el empleo $(71,6)$ y las ramas, que en términos relativos cobran más importancia, son Servicios empresariales, Industria, agricultura y pesca. Muchos de ellos trabajan fuera de Cataluña.

Matriz 8: Son 720 titulados (8,6\%), hijos de directores, con la máxima calidad de inserción laboral $(71,8)$, formalmente en movilidad descendente pues sólo les queda ser directores. Se trata de un grupo donde los padres poseen altos niveles educativos, en términos relativos se destacan los que han estudiado en la Universidad Pompeu Fabra, tienen 29 años en promedio y están ligados a titulaciones como Medicina y Veterinaria, más insertos relativamente en Sanidad y que durante la carrera han trabajado a tiempo parcial en un trabajo relacionado con el estudio.

Tabla 10. Peso de cada titulación en las Matrices 7 y 8 (selección de las que son más importantes)

\begin{tabular}{|c|c|c|c|}
\hline Matriz 7 & $\%$ & Matriz 8 & $\%$ \\
\hline $\begin{array}{l}\text { Llicenciatura en Administració i Direcció } \\
\text { d'Empreses }\end{array}$ & 4,6 & Llicenciat en Medicina & 7,1 \\
\hline Llicenciat en Medicina & 4,2 & Llicenciatura en Dret & 5,1 \\
\hline Llicenciatura en Dret & 4,2 & Diplomatura en Ciències Empresarials & 3,1 \\
\hline Llicenciatura en Economia & 3,3 & Diplomatura en Infermeria & 3,1 \\
\hline Diplomatura en Ciències Empresarials & 3,1 & Llicenciatura en Biologia & 2,9 \\
\hline Enginyeria de Telecomunicacions & 2,8 & Mestre (Educació Infantil) & 2,9 \\
\hline Mestre (Educació Primària) & 2,7 & Enginyeria en Informàtica & 2,8 \\
\hline Mestre (Educació Infantil) & 2,6 & $\begin{array}{l}\text { Llicenciatura en Administració i Direcció } \\
\text { d'Empreses }\end{array}$ & 2,6 \\
\hline Mestre (Llengua Estrangera) & 2,1 & Mestre (Educació Física) & 2,4 \\
\hline Enginyeria en Informàtica & 2,0 & Diplomatura en Educació Social & 2,2 \\
\hline Enginyeria Industrial & 1,9 & $\begin{array}{l}\text { Enginyeria Tècnica en Informàtica de } \\
\text { Gestió }\end{array}$ & 2,1 \\
\hline Llicenciat en Psicologia & 1,9 & Llicenciatura en Economia & 2,1 \\
\hline Llicenciatura en Biologia & 1,9 & Mestre (Llengua Estrangera) & 2,1 \\
\hline Llicenciatura en Periodisme & 1,9 & $\begin{array}{l}\text { Enginyeria Tècnica en Informàtica de } \\
\text { Sistemes }\end{array}$ & 1,9 \\
\hline Mestre (Educació Física) & 1,8 & Mestre (Educació Primària) & 1,9 \\
\hline Diplomatura en Infermeria & 1,7 & Enginyeria de Telecomunicacions & 1,8 \\
\hline Llicenciat en Ciències Ambientals & 1,7 & Llicenciat en Psicologia & 1,8 \\
\hline Diplomatura en Relacions Laborals & 1,5 & Llicenciatura en Periodisme & 1,8 \\
\hline $\begin{array}{l}\text { Enginyeria Tècnica Industrial (Electrònica } \\
\text { Industrial) }\end{array}$ & 1,5 & Enginyeria Química & 1,7 \\
\hline $\begin{array}{l}\text { Enginyeria Química } \\
\text { Enginyeria Tècnica Industrial (Mecànica) }\end{array}$ & $\begin{array}{l}1,5 \\
1,5\end{array}$ & & \\
\hline
\end{tabular}

Fuente: elaboración propia sobre la base de AQU, 2011

\section{Conclusiones}

Dentro de la línea de investigación que aborda la movilidad ocupacional de los graduados universitarios, presentamos un primer resultado sobre titulados entrevistados en 2011 y que en general han tenido la posibilidad de insertarse en el mercado laboral antes de que la crisis 
manifestara toda su fuerza. Seguidamente presentamos las respuestas que hemos encontrado a las inquietudes planteadas inicialmente.

En primer lugar, el conjunto de graduados en 2006-2007 en las universidades públicas catalanas presentan un importante nivel de movilidad con respecto a sus padres, y en concreto, el $60 \%$ de ellos superan el nivel ocupacional de los mismos. También se observa que el origen social condiciona en forma muy débil la posición alcanzada por el graduado, esto significa que, dada una misma posición social de destino, provienen en proporciones similares de todos los orígenes sociales. Este hecho es muy relevante, pues muestra la importante función que ha tenido la universidad y en ese sentido evidencia que los recursos brindados por la universidad junto a ciertos rasgos meritocráticos del mercado de trabajo, contribuyen a afirmar que esta generación de graduados posee un grado de equidad importante en el proceso de su inserción laboral.

En segundo lugar, hemos podido constatar que los modelos teóricos tradicionales de movilidad relativa propuestos para analizar las sociedades avanzadas no son adecuados para definir un perfil específico como es el de graduados universitarios. Este resultado es esperable, pues cabe pensar que sean los universitarios los que aporten un mayor grado de movilidad al conjunto de la sociedad y en ese sentido, aporten mayor fluidez y a su vez, se diferencien de los patrones clásicos encontrados para la sociedad en su conjunto.

En tercer lugar, hemos desarrollado un modelo topológico que se ajusta al perfil de los graduados universitarios bajo análisis, por tanto da cuenta de las particularidades de este colectivo, en concreto describe 8 patrones, que podemos sintetizar en tres grandes subgrupos:

a) Titulados que aún no han rentabilizado la educación superior en términos de movilidad ocupacional (titulados con barreras relativas a la movilidad).

b) Titulados que mayormente han rentabilizado la educación superior sin ventaja de origen (titulados con deseabilidad relativa de movilidad).

c) Titulados que han rentabilizado la educación superior con alta ventaja de origen (titulados con ventajas relativas de movilidad).

La matriz topológica desarrollada para analizar los perfiles de los titulados permite caracterizar sus diferencias internas, que hemos sintetizado en tres grupos, y ha mostrado ser adecuada para dar cuenta de las particularidades de esta generación de graduados.

Este estudio no pudo ser repetido a ningún nivel, toda vez que la encuesta realizada por AQU en Cataluña en 2014 y la primera Encuesta de Inserción Laboral de Titulados Universitarios del INE también del 2014, no realizaron las preguntas sobre la ocupación de los padres de los 
titulados, insumo fundamental para los análisis de movilidad intergeneracional. Por tanto, a la vez que original, este trabajo se erige como pionero en este tipo de análisis y pretende corroborar el patrón topológico aquí analizado en futuros estudios.

Disponer de datos sobre graduados universitarios de diferentes cohortes en España y avanzar en la contribución de éstas a la movilidad social es un desafío que pretendemos continuar realizando en la medida que existan políticas públicas interesadas en la producción de información social que posibiliten la investigación sobre este fenómeno. Tenemos que avanzar sobre este tema, que no es otro que la contribución de la educación superior a la movilidad social.

\section{Referencias}

Albert, C. (1998). Higher Education Demand in Spain: The Influence of Labour Market Signals and Family Background." Working Paper EC98-17. Instituto Valenciano de Investigaciones Económicas, Valencia.

Atria, R. (2004). Estructura ocupacional, estructura social y clases sociales. Serie de Políticas Sociales Nº6, CEPAL. Santiago de Chile.

Becher, T. (1994). The significance of Disciplinary Differences. Studies in Higher Education 19 (2): 151- 161

Becker, G. (1975). Human capital. Nueva York: NBER.

Beduwe, C. y Planas, J. (2003). Educational Expansion and Labour Market - EDEX. Luxembourg: Office for Official Publications of the European Communities.

Bernstein, B. (1988). Clases, códigos y control. Madrid: Arkal.

Boado Martínez, M. (2010). Modelos de movilidad social: una aproximación al funcionamiento de la desigualdad social en ciudades del Uruguay, Pp. 81-92 in El Uruguay desde la Sociología Vol. VIII, Montevideo: Facultad de Ciencias Sociales, Universidad de la República.

Boado Martínez, M. (2011). Re-revisión de análisis de tablas e introducción a modelos loglineales. Montevideo: Universidad de la República. Mimeo.

Bourdieu, P. and Passeron, J.C.. (1990). Reproduction in Education, Society, and Culture. London; Newbury Park, Calif.: Sage in association with Theory Culture \& Society Dept. of Administrative and Social Studies Teesside Polytechnic. [1977]

Breen, R. (2004). Social Mobility in Europe. Oxford: Oxford Univ. Press. 
Breen, R. and Goldthorpe, J.H. (1997). Explaining Educational Differentials: Towards a Formal Rational Action Theory. Rationality \& Society 9: 273-305.

Breen, R. and Goldthorpe, J.H. (2001). Class, mobility and merit: the experience of two British birth cohorts. European Sociological Review. Pp.17:81-101

Breen, R. and Luijkx, R. (2004). Conclusions. Pp. 383-410 in Breen, R. comp. Social Mobility in Europe. Oxford: Oxford Univ. Press.

Breen, R. and Jonsson, J. (2005). Inequality of Opportunity in Comparative Perspective: Recent Research on Educational. Annual Review of Sociology 31: 223-243.

Carabaña, J. (1999). Dos estudios sobre movilidad intergeneracional. Madrid: Fundación Argentaria.

Corominas Rovira, E., Villar Hoz, E., Saurina Canals, C. y Fàbregas Alcaire, M. (2007). El mercat laboral qualificat i la qualitat de l'ocupació. En Educació superior $i$ treball a Catalunya. Anàlisi dels factors d'inserció laboral. Barcelona: Agència per a la Qualitat del Sistema Universitari de Catalunya.

Echeverría Zabalza, J. (1999). La Movilidad Social en España, 1940-1991. Madrid: Ediciones Istmo.

Erikson R., Golthorpe, J.H. and Portocarero, L. (1979). Intergenerational Class Mobility in Three Western European Societies: England, France and Sweden. The British Journal of Sociology 30 (4): 415-441.

Erikson R. and Golthorpe, J.H. (1993). The constant flux: A Study of Class Mobility in Industrial Societies. New York: Oxford University Press.

Fachelli, S. (2011). Informe de avance de investigación sobre Itinerarios Universitarios Equidad y Movilidad Ocupacional (ITUNEQMO) Ponencia presentada en el Seminario Interno del GRET. Octubre, Universitat Autònoma de Barcelona.

Fachelli, S. y López-Roldán, P. (2012). Análisis de datos estadísticos. Análisis de movilidad social. Universitat Autònoma de Barcelona. Consulta 5 Marzo 2013 (http://ddd.uab.cat/record/88747)

Fachelli y López-Roldán (2015). ¿Somos más móviles incluyendo a la mitad invisible? Análisis de la movilidad social intergeneracional en España en 2011. Revista Española de Investigaciones Sociológicas, 150, abril-junio, 41-70.

Fachelli, S. y Planas, J. (2011). Equidad y movilidad intergeneracional de los titulados universitarios catalanes. Papers. Revista de Sociologia 96 4: 1281-1305. 
Fachelli, S. y Planas, J. (2012). Equidad e inserción profesional de los universitarios: de la expansión a la crisis. Ponencia presentada en el Seminario Interno del GRET. Febrero, Universitat Autònoma de Barcelona.

Featherman, D.L., Jones, F.L. and Hauser, R.M. (1975). Assumptions of Social Mobility Research in the US: The case of Occupational Status. Social Science Research 4: 329360.

Gerber, T.P. (2003). Loosening links? School-to work transitions and institutional change in Russia since 1970. Social Forces 82: 241-76

Glass, D. V. (1949). Social Mobility in Britain. London: Routledge.

Goodman, L. A. (1972). A General Model for the Analysis of Surveys. American Journal of Sociology 77 6: 1035-1086.

Goldthorpe, J. (2007). On Sociology: numbers, narrative and the integration of research and theory. California: Satanford Univesity Press.

Goldthorpe J.H. and Hope, K. (1974). Pie Social Grading of Occupations: A New Approach and Scale. Oxford: Oxford Clarendon Press.

Grusky, D. B. and Hauser. R.M. (1984). Comparative social mobility revisited: Models of convergence and divergence in 16 countries. American Sociological Review 49 (1): 2022.

Hauser, R. M. and Featherman, D.L. (1977). The Process of Stratification: Trends and Analyses. New York: Academic Press.

Hauser, R. M. (1978). A Structural Model of the Mobility Table. Social Forces, 56: 919-953.

Hauser, R. M. (1979). Some exploratory methods for modeling mobility tables and other crosclassified data. Pp. 423-458 in: K. F: Schuessler (Ed.), Sociological Methodology 1980, San Francisco: Jose-Bass.

Hauser, R.M., Warren, J.R., Huang, M.H. and Carter, W.Y. (2000). Occupational status, education and social mobility in the meritocracy. Pp. 179-229 in Meritocracy and Economic Inequality, ed. K Arrow, S Bowles, S Durlauf. Princeton, NJ: Univ. Princeton Press.

Hout, M. (1983). Mobility Tables. Beverly Hills (California): Sage.

Hout, M. (1988). More universalism, less structural mobility: the American occupational structure in the 1980s. American Journal of Sociology 93: 1358-1400 
Jonsson, J.O. (1996). Stratification in post-industrial society: Are educational qualifications of growing importance?. Pp. 113-144 in Erikson and Jonsson. Can Education be Equalized? Boulder, CO: Westview.

Jorrat, J. R. (1987). Exploraciones sobre movilidad ocupacional intergeneracional masculina en el Gran Buenos Aires. Desarrollo Económico 27: 261-278.

Jorrat, J. R. (1997). En la huella de los padres: Movilidad ocupacional en el Buenos Aires de 1980. Desarrollo Económico 37: 91-116.

Jorrat, J. R. (2008). Exploraciones sobre movilidad de clases en Argentina: 2003-2004. Documento de trabajo $N^{\circ}$ 52. Instituto de Investigaciones Gino Germani, Universidad de Buenos Aires.

Kodde, D. (1986). Uncertainty and the Demand for Education, Review of Economics and Statistics 68 (3): 460 - 67.

Lipset, S. M. and Zetterberg, H.L. (1959). Social mobility in industrial societies. Pp.11-75 in S. M. Lipset y R. Bendix, Social mobility in industrial society. Berkeley: University of California Press.

Marqués Perales, I. y Herrera-Usagre, Y. (2010). ¿Somos más móviles? Nuevas evidencias sobre la movilidad intergeneracional de clase en España en la segunda mitad del siglo XX. Revista Española de Investigaciones Sociológicas 131: 43-73.

Martínez Celorrio, X. y Marín Saldo, A. (2010). Educació i mobilitat social a Catalunya. Barcelona. Polítiques, 71. Barcelona: Fundació Jaume Bofill.

Merton, R. (1980). Teoría y Estructura Sociales. México: Fondo de Cultura Económica.

Morineau, A. (1984). Note sur la caractérisation statistique d'une classe et les valeurstest. Bulletin Technique du Centre de Statistique et d'Informatique Appliquées 2 (1-2): 20-27.

Navarro-Cendejas, J. y Fachelli, S. (2017). The impact of economic crisis on graduates' transition to employment. Artículo en revision.

Planas, J. y Fachelli, S. (2010). Les universitats catalanes factor d'equitat $i$ de mobilitat professional. Una anàlisi sobre les relacions entre el estatus familiar, el bagatge acadèmic i l'inserció professional l'any 2008, dels titulats de l'any 2004 a les universitats catalanes. Barcelona: AQU. 
Sanchez-Gelabert, A. (2011). Itineraris universitaris. Una aproximació als factors associats a l'abandó. Trabajo de Fin de Máster, Departament de Sociologia, Universitat Autònoma de Barcelona.

Treiman, D.J. and Yip, K.B. (1989). Educational and occupational attainment in 21 countries. Pp. 373-94 in Cross-National Research in Sociology, edited by M.L. Kohn. Newbury Park, CA: Sage.

Ustrell, M. (2012). Les estratègies d'accés a la universitat via Cicle Formatiu de Grau Superior. Trabajo de Fin de Máster, Departament de Sociologia, Universitat Autònoma de Barcelona.

Vallet, L.A. (2004). Change in intergenerational class mobility in France from the 1970s to the 1990s and its explanation: an analysis following the CASMIN approach. Pp. 115-148 in Social Mobility in Europe, edited by Breen. Oxford: Oxford Univ. Press.

Warren, J.R., Hauser, R.M. and Sheridan. J.T. (2002). Occupational stratification across the life course: evidence from the Wisconsin Longitudinal Study. American Sociological Review 67: $432-455$

Whelan, C.T. and Layte, R. (2002). Late industrialization and the increased merit selection hypothesis: Ireland as a test case. European Sociological Review 18: 35-50. 


\section{Anexo 1. Muestra diseñada por AQU y utilizada en este estudio.}

Los datos provienen de la encuesta sobre la inserción laboral los graduados de las universidades catalanas, elaboradas por la Agencia para la Calidad del Sistema Universitario de Cataluña (AQU). La encuesta se realizó en el primer trimestre de 2011 con las personas que se titularon en el curso 2007.

A diferencia de la encuesta anterior (2008) donde el $96 \%$ de los titulados provenían de universidades públicas, la del 2011 abarcó un grupo más amplio de universidades privadas (80\% públicas y $20 \%$ privadas).

El proyecto en el que nos encontramos inmersos, aborda únicamente las universidades públicas. De esta manera la población y la muestra seleccionada se muestran a continuación y para un mayor detalle se pueden consultar los trabajas de AQU (2008 y 2011).

Tabla 11. Población, muestra y error muestral.

\begin{tabular}{ccc}
\hline & Encuesta 2011 & \\
\hline Población de & Muestra & Error \\
referencia & universidades & muestral \\
& públicas & \\
21.596 & 11.843 & $0.62 \%$ \\
\hline Fuente: AQU 2011. & &
\end{tabular}

Concretamente la cantidad de graduados que trabajan a tiempo completo son 9.387. En el caso del análisis de la movilidad debemos tener en cuenta que trabajamos con los ocupados pero cuyos padres hayan dado información sobre su ocupación, esto define nuestra muestra final en 8.391 personas. 


\section{Anexo 2. Resultados de los titulados por matriz}

Tabla 12. Variables seleccionadas para analizar las diferentes matrices. Resultados del conjunto de los titulados

\begin{tabular}{|c|c|c|c|c|c|}
\hline \multicolumn{2}{|c|}{ Sexo, edad y nivel educativo de los padres } & $\begin{array}{ll}\% \\
58,8\end{array}$ & \multicolumn{2}{|c|}{ Variables vinculadas al proceso de estudio } & $\%$ \\
\hline Sexo & 2 Varón & \multirow[t]{2}{*}{41,2} & \multirow{2}{*}{$\begin{array}{l}\text { Estudios y } \\
\text { trabajo } \\
\text { durante la } \\
\text { carrera }\end{array}$} & $\begin{array}{l}1 \text { Estudiante } \\
2 \text { Tiempo Parcial relacionado } \\
3 \text { Tiempo Parcial no relacionado } \\
4 \text { Tiempo Completo relacionado }\end{array}$ & $\begin{array}{l}30,9 \\
25,0 \\
13,5 \\
22,8\end{array}$ \\
\hline Edad & Media & & & 5 Tiem. Completo no relacionado & 7,8 \\
\hline $\begin{array}{l}\text { Nivel } \\
\text { educativo de } \\
\text { los padres }\end{array}$ & $\begin{array}{l}1 \text { Primario o sin estudios } \\
2 \text { Uno con estudios medios } \\
3 \text { Dos con estudios medios } \\
4 \text { Uno con estudios superiores } \\
5 \text { Dos con estudios superiores } \\
\end{array}$ & \begin{tabular}{l|}
38,1 \\
12,7 \\
18,0 \\
16,6 \\
14,5 \\
\end{tabular} & \multirow{2}{*}{$\begin{array}{l}\text { Universidade } \\
\text { s publicas }\end{array}$} & $\begin{array}{l}1 \text { Universidad de Barcelona } \\
2 \text { U. Autónoma de Barcelona } \\
3 \text { U. Politécnica de Cataluña } \\
4 \text { U. Pompeu Fabra } \\
5 \text { U. de Girona }\end{array}$ & $\begin{array}{r}26,4 \\
21,8 \\
16,6 \\
7,2 \\
8,8\end{array}$ \\
\hline \multicolumn{2}{|c|}{ Variables vinculadas con la ocupación } & $\%$ & & $\begin{array}{l}6 \text { U. de Lleida } \\
7 \text { U. Rovira Virgili }\end{array}$ & $\begin{array}{r}7,0 \\
12,2 \\
\end{array}$ \\
\hline $\begin{array}{l}\text { Nivel de } \\
\text { estudios } \\
\text { requeridos }\end{array}$ & $\begin{array}{l}1 \text { Titulación específica } \\
2 \text { Titulación universitaria } \\
3 \text { Ninguna titulación }\end{array}$ & $\begin{array}{l}61,7 \\
21,0 \\
17,2 \\
\end{array}$ & Ciclo & $\begin{array}{l}1 \text { Primer Ciclo } \\
2 \text { Primero y Segundo ciclo } \\
3 \text { Segundo ciclo }\end{array}$ & $\begin{array}{l}42,8 \\
42,5 \\
14,7 \\
\end{array}$ \\
\hline \begin{tabular}{|l|} 
Ámbito de la \\
empresa
\end{tabular} & $\begin{array}{l}1 \text { Publico } \\
2 \text { Privado }\end{array}$ & $\begin{array}{l}33,4 \\
66,6 \\
\end{array}$ & \multirow{2}{*}{$\begin{array}{l}\text { Clasificación } \\
\text { académica/pr } \\
\text { ofesional de } \\
\text { titulaciones }\end{array}$} & $\begin{array}{l}1 \text { Blandas aplicadas } \\
2 \text { Blandas no aplicadas }\end{array}$ & $\begin{array}{l}35,4 \\
13,0\end{array}$ \\
\hline \multirow[b]{2}{*}{$\begin{array}{l}\text { Lugar donde } \\
\text { trabaja }\end{array}$} & $\begin{array}{l}1 \text { Barcelona } \\
2 \text { Tarragona }\end{array}$ & $\begin{array}{l}66,1 \\
10,9\end{array}$ & & $\begin{array}{l}3 \text { Duras aplicadas } \\
4 \text { Duras no aplicadas }\end{array}$ & $\begin{array}{r}46,9 \\
4,7 \\
\end{array}$ \\
\hline & $\begin{array}{l}3 \text { Girona } \\
4 \text { Lleida } \\
5 \text { Fuera de Catalunya }\end{array}$ & $\begin{array}{l}9,1 \\
5,7 \\
8,2\end{array}$ & \multirow[b]{2}{*}{$\begin{array}{l}\text { Titulaciones } \\
\text { por tipo }\end{array}$} & $\begin{array}{l}1 \text { Licenciatura } \\
2 \text { Ingenieria } \\
3 \text { Diplomatura }\end{array}$ & $\begin{array}{l}41,9 \\
11,2 \\
27,8\end{array}$ \\
\hline \multirow{2}{*}{$\begin{array}{l}\text { Rama } \\
\text { actividad } \\
\text { económica }\end{array}$} & $\begin{array}{l}1 \text { Industria, agricultura y pesca } \\
2 \text { Construcción } \\
3 \text { Comercio, transport y hostelería } \\
4 \text { TIC's }\end{array}$ & $\begin{array}{r}14,0 \\
5,0 \\
7,2 \\
8,3\end{array}$ & & $\begin{array}{l}4 \text { Ing. Técnica } \\
5 \text { Medicina y veterinaria } \\
6 \text { Arquitectura } \\
7 \text { Odontología }\end{array}$ & $\begin{array}{r}15,1 \\
3,2 \\
, 7\end{array}$ \\
\hline & $\begin{array}{l}5 \text { Finanzas } \\
6 \text { Serv. empresariales } \\
7 \text { Servicio público } \\
8 \text { Educación y cultura } \\
9 \text { Sanidad y Atención social }\end{array}$ & $\begin{array}{r}7,2 \\
12,1 \\
7,6 \\
24,1 \\
14,4 \\
\end{array}$ & \multirow[t]{2}{*}{$\begin{array}{l}\text { Duración de } \\
\text { los estudios }\end{array}$} & $\begin{array}{l}11 \text { año } \\
22 \text { años } \\
33 \text { años } \\
44 \text { años } \\
55 \text { años }\end{array}$ & $\begin{array}{r}5,1 \\
19,4 \\
17,6 \\
18,1 \\
14,7\end{array}$ \\
\hline $\begin{array}{l}\text { Calidad de la } \\
\text { ocupación }\end{array}$ & Entre 0 y 100 (media general) & 66,7 & & $\begin{array}{l}66 \text { años } \\
77 \text { años o más }\end{array}$ & $\begin{array}{l}10,5 \\
14,7\end{array}$ \\
\hline
\end{tabular}

clasificación académica profesional sigue los criterios desarrollados por T. Becher (1994)

Fuente: elaboración propia sobre la base de AQU, 2011 
Tabla 13. Características generales de los titulados según cada matriz 


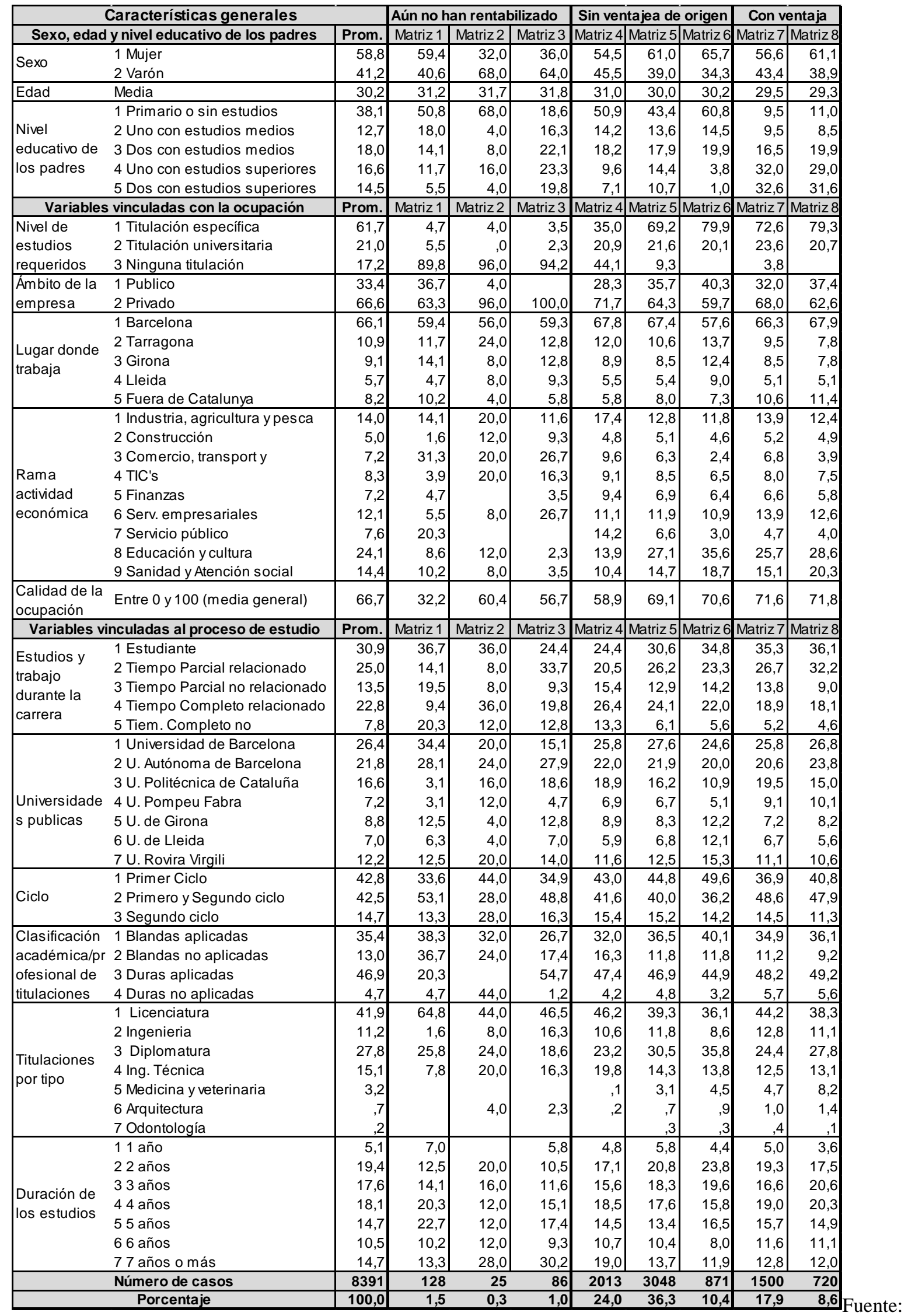

elaboración propia sobre la base de AQU (2011) 
Tabla 14. Distribución de titulaciones por matriz

\begin{tabular}{|c|c|c|c|c|c|c|c|c|c|c|}
\hline Porcentaje de cada grupo sobre la Titulación & Total & MTU1 & MTU2 & MTU3 & MTU4 & MTU5 & MTU6 & MTU7 & MTU8 & Total \\
\hline Arquitectura & 60 & 0,0 & 1,7 & 3,3 & 6,7 & 33,3 & 13,3 & 25,0 & 16,7 & 100 \\
\hline Arquitectura Tècnica & 100 & 3,0 & 0,0 & 2,0 & 29,0 & 38,0 & 13,0 & 9,0 & 6,0 & 100 \\
\hline Belles Arts & 54 & 5,6 & 3,7 & 3,7 & 33,3 & 22,2 & 9,3 & 16,7 & 5,6 & 100 \\
\hline Biblioteconomia i Documentació & 38 & 5,3 & 0,0 & 0,0 & 28,9 & 21,1 & 5,3 & 23,7 & 15,8 & 100 \\
\hline Criminologia & 97 & 3,1 & 1,0 & 1,0 & 52,6 & 26,8 & 4,1 & 9,3 & 2,1 & 100 \\
\hline Diplomat en Logopèdia & 17 & 0,0 & 0,0 & 0,0 & 17,6 & 35,3 & 11,8 & 23,5 & 11,8 & 100 \\
\hline Diplomatura d'Òptica i Optometria & 48 & 0,0 & 0,0 & 0,0 & 16,7 & 45,8 & 10,4 & 14,6 & 12,5 & 100 \\
\hline Diplomatura de Màquines Navals & 6 & 0,0 & 0,0 & 0,0 & 33,3 & 16,7 & 0,0 & 16,7 & 33,3 & 100 \\
\hline Diplomatura de Navegació Marítima & 9 & 11,1 & 0,0 & 0,0 & 11,1 & 11,1 & 0,0 & 55,6 & 11,1 & 100 \\
\hline Diplomatura en Ciències Empresarials & 405 & 2,0 & 0,5 & 2,7 & 36,3 & 33,1 & 8,6 & 11,4 & 5,4 & 3100 \\
\hline Diplomatura en Educació Social & 138 & 0,7 & 0,7 & 0,0 & 20,3 & 42,0 & 9,4 & 15,2 & 11,6 & 100 \\
\hline Diplomatura en Estadística & 33 & 0,0 & 0,0 & 0,0 & 21,2 & 39,4 & 18,2 & 12,1 & 9,1 & 100 \\
\hline Diplomatura en Gestió i Administració Pública & 65 & 6,2 & 1,5 & 1,5 & 44,6 & 36,9 & 1,5 & 7,7 & 0,0 & 100 \\
\hline Diplomatura en Infermeria & 181 & 0,0 & 0,0 & 0,0 & 8,3 & 49,7 & 16,0 & 13,8 & 12,2 & 100 \\
\hline Diplomatura en Relacions Laborals & 231 & 3,5 & 0,9 & 0,4 & 40,3 & 32,9 & 7,8 & 10,0 & 4,3 & 100 \\
\hline Diplomatura en Treball Social & 110 & 1,8 & 0,0 & 0,0 & 24,5 & 36,4 & 13,6 & 13,6 & 10,0 & 100 \\
\hline Diplomatura en Turisme & 43 & 4,7 & 0,0 & 2,3 & 44,2 & 23,3 & 7,0 & 7,0 & 11,6 & 100 \\
\hline Enginyeria Agronòmica & 52 & 0,0 & 0,0 & 5,8 & 17,3 & 48,1 & 15,4 & 9,6 & 3,8 & 100 \\
\hline Enginyeria de Camins, Canals i Ports & 70 & 0,0 & 0,0 & 0,0 & 11,4 & 42,9 & 5,7 & 28,6 & 11,4 & 100 \\
\hline Enginyeria de Forests & 31 & 3,2 & 0,0 & 0,0 & 29,0 & 32,3 & 9,7 & 16,1 & 9,7 & 100 \\
\hline Enginyeria de Materials & 22 & 0,0 & 0,0 & 0,0 & 13,6 & 40,9 & 13,6 & 22,7 & 9,1 & 100 \\
\hline Enginyeria de Mines & 2 & 0,0 & 0,0 & 0,0 & 100,0 & 0,0 & 0,0 & 0,0 & 0,0 & 100 \\
\hline Enginyeria de Telecomunicacions & 144 & 0,0 & 0,0 & 2,1 & 24,3 & 32,6 & 2,8 & 29,2 & 9,0 & 100 \\
\hline Enginyeria Electrònica & 43 & 0,0 & 0,0 & 2,3 & 25,6 & 34,9 & 11,6 & 20,9 & 4,7 & 100 \\
\hline Enginyeria en Automàtica i Electrònica Industrial & 37 & 2,7 & 2,7 & 0,0 & 18,9 & 37,8 & 8,1 & 16,2 & 13,5 & 100 \\
\hline Enginyeria en Informàtica & 224 & 0,0 & 0,0 & 2,7 & 25,4 & 42,0 & 7,6 & 13,4 & 8,9 & 100 \\
\hline Enginyeria en Organització Industrial & 71 & 0,0 & 0,0 & 1,4 & 25,4 & 38,0 & 4,2 & 23,9 & 7,0 & 100 \\
\hline Enginyeria Geològica & 12 & 0,0 & 0,0 & 0,0 & 25,0 & 50,0 & 8,3 & 16,7 & 0,0 & 100 \\
\hline Enginyeria Industrial & 125 & 0,0 & 0,8 & 0,0 & 18,4 & 38,4 & 12,8 & 23,2 & 6,4 & 100 \\
\hline Enginyeria Química & 105 & 0,0 & 0,0 & 0,0 & 26,7 & 33,3 & 7,6 & 21,0 & 11,4 & 100 \\
\hline Enginyeria Tèc. de Telecomunicacions (Sist. de & 25 & 0,0 & 0,0 & 0,0 & 32,0 & 40,0 & 4,0 & 16,0 & 8,0 & 100 \\
\hline Enginyeria Tèc. de Telecomunicacions (Sistemes & 67 & 0,0 & 0,0 & 0,0 & 41,8 & 26,9 & 7,5 & 16,4 & 7,5 & 100 \\
\hline Enginyeria Tèc. de Telecomunicacions (So i & 29 & 0,0 & 3,4 & 0,0 & 27,6 & 41,4 & 3,4 & 17,2 & 6,9 & 100 \\
\hline Enginyeria Tèc. de Telecomunicacions & 46 & 0,0 & 0,0 & 2,2 & 37,0 & 28,3 & 6,5 & 17,4 & 8,7 & 100 \\
\hline Enginyeria Tècnica Aeronàutica (Aeronavegació) & 18 & 0,0 & 0,0 & 0,0 & 27,8 & 38,9 & 5,6 & 27,8 & 0,0 & 100 \\
\hline Enginyeria Tècnica Agrícola (Explotacions & 19 & 0,0 & 0,0 & 0,0 & 26,3 & 26,3 & 21,1 & 5,3 & 21,1 & 100 \\
\hline Enginyeria Tècnica Agrícol & 15 & 0,0 & 0,0 & 0,0 & 40,0 & 33,3 & 6,7 & 20,0 & 0,0 & 100 \\
\hline Enginyeria Tècnica Agrícola (Indústries Agràries i & 52 & 1,9 & 1,9 & 0,0 & 23,1 & 30,8 & 11,5 & 13,5 & 17,3 & 100 \\
\hline Enginyeria Tècnica Agrícola (Mecanització i & 4 & 0,0 & 0,0 & 0,0 & 25,0 & 25,0 & 25,0 & 25,0 & 0,0 & 100 \\
\hline Enginyeria Tècnica d'Obres Públiques & 50 & 0,0 & 0,0 & 0,0 & 30,0 & 34,0 & 6,0 & 18,0 & 12,0 & 100 \\
\hline Enginyeria Tècnica de Mines (Explotació de & 11 & 0,0 & 0,0 & 0,0 & 9,1 & 45,5 & 18,2 & 18,2 & 9,1 & 100 \\
\hline Enginyeria Tècnica en Informàtica de Gestió & 173 & 0,6 & 0,0 & 4,0 & 33,5 & 28,3 & 12,7 & 12,1 & 8,7 & 100 \\
\hline Enginyeria Tècnica en Informàtica de Sistemes & 179 & 0,6 & 0,0 & 1,1 & 30,2 & 38,5 & 10,1 & 11,7 & 7,8 & 100 \\
\hline Enginyeria Tècnica en Topografia & 18 & 0,0 & 0,0 & 0,0 & 16,7 & 44,4 & 5,6 & 22,2 & 11,1 & 100 \\
\hline Enginyeria Tècnica Forestal (Explotacions & 20 & 5,0 & 0,0 & 0,0 & 25,0 & 40,0 & 0,0 & 25,0 & 5,0 & 100 \\
\hline Enginyeria Tècnica Forestal (Indústries Forestals) & 1 & 0,0 & 0,0 & 0,0 & 0,0 & 0,0 & 0,0 & 100,0 & 0,0 & 100 \\
\hline Enginyeria Tècnica Industrial (Electricitat) & 65 & 0,0 & 4,6 & 1,5 & 35,4 & 29,2 & 7,7 & 16,9 & 4,6 & 100 \\
\hline Enginyeria Tècnica Industrial (Electrònica & 117 & 0,0 & 0,0 & 0,0 & 33,3 & 35,9 & 5,1 & 19,7 & 6,0 & 100 \\
\hline Enginyeria Tècnica Industrial (Mecànica) & 136 & 0,0 & 0,0 & 0,7 & 27,2 & 36,8 & 14,0 & 16,2 & 5,1 & 100 \\
\hline Enginyeria Tècnica Industrial (Química Industrial)) & 101 & 3,0 & 0,0 & 0,0 & 37,6 & 38,6 & 6,9 & 8,9 & 5,0 & 100 \\
\hline Enginyeria Tècnica Industrial (Tèxtil) & 6 & 0,0 & 0,0 & 0,0 & 50,0 & 16,7 & 0,0 & 16,7 & 16,7 & 100 \\
\hline Enginyeria Tècnica Naval en Propulsió i Serveis & 11 & 0,0 & 0,0 & 0,0 & 27,3 & 27,3 & 9,1 & 36,4 & 0,0 & 100 \\
\hline Enologia & 22 & 4,5 & 0,0 & 0,0 & 27,3 & 31,8 & 9,1 & 22,7 & 4,5 & 100 \\
\hline Farmàcia & 67 & 1,5 & 0,0 & 0,0 & 14,9 & 41,8 & 7,5 & 26,9 & 7,5 & 100 \\
\hline Filologia Alemanya & 6 & 0,0 & 0,0 & 0,0 & 33,3 & 33,3 & 16,7 & 16,7 & 0,0 & 100 \\
\hline Filologia Àrab & 2 & 0,0 & 0,0 & 0,0 & 50,0 & 50,0 & 0,0 & 0,0 & 0,0 & 100 \\
\hline Filologia Eslava & 1 & 0,0 & 0,0 & 0,0 & 0,0 & 0,0 & 0,0 & 100,0 & 0,0 & 100 \\
\hline Filologia Hebrea & 1 & 0,0 & 0,0 & 0,0 & 0,0 & 0,0 & 100,0 & 0,0 & 0,0 & 100 \\
\hline Fisioteràpia & 26 & 3,8 & 0,0 & 0,0 & 3,8 & 46,2 & 15,4 & 26,9 & 3,8 & 100 \\
\hline
\end{tabular}

Fuente: elaboración propia sobre la base de AQU (2011) 


\begin{tabular}{|c|c|c|c|c|c|c|c|c|c|c|}
\hline Porcentaje de cada grupo sobre la Titulación & Total & MTU1 & MTU2 & MTU3 & MTU4 & MTU5 & MTU6 & MTU7 & MTU8 & Total \\
\hline Investigació i Tècniques de Mercat & 59 & 1,7 & 0,0 & 0,0 & 25,4 & 32,2 & 8,5 & 27,1 & 5,1 & 100 \\
\hline Lingüística & 11 & 0,0 & 0,0 & 0,0 & 27,3 & 36,4 & 9,1 & 27,3 & 0,0 & 100 \\
\hline Llicenciat en Antropologia Social i Cultural & 75 & 1,3 & 0,0 & 0,0 & 32,0 & 40,0 & 12,0 & 12,0 & 2,7 & 100 \\
\hline Llicenciat en Bioquímica & 49 & 0,0 & 0,0 & 2,0 & 16,3 & 51,0 & 16,3 & 12,2 & 2,0 & 100 \\
\hline Llicenciat en Biotecnologia & 18 & 0,0 & 0,0 & 0,0 & 16,7 & 38,9 & 5,6 & 33,3 & 5,6 & 100 \\
\hline Llicenciat en Ciències Ambientals & 82 & 0,0 & 0,0 & 0,0 & 20,7 & 26,8 & 14,6 & 30,5 & 7,3 & 100 \\
\hline Llicenciat en Documentació & 38 & 2,6 & 0,0 & 0,0 & 26,3 & 42,1 & 5,3 & 18,4 & 5,3 & 100 \\
\hline Llicenciat en Física & 48 & 0,0 & 0,0 & 0,0 & 22,9 & 29,2 & 10,4 & 22,9 & 14,6 & 100 \\
\hline Llicenciat en Geologia & 38 & 2,6 & 0,0 & 0,0 & 44,7 & 26,3 & 2,6 & 21,1 & 2,6 & 100 \\
\hline Llicenciat en Matemàtiques & 51 & 0,0 & 0,0 & 0,0 & 29,4 & 43,1 & 3,9 & 15,7 & 7,8 & 100 \\
\hline Llicenciat en Medicina & 224 & 0,0 & 0,0 & 0,0 & 0,4 & 33,9 & 14,7 & 28,1 & 22,8 & 100 \\
\hline Llicenciat en Pedagogia & 113 & 3,5 & 0,0 & 0,0 & 32,7 & 31,0 & 8,0 & 17,7 & 7,1 & 3100 \\
\hline Llicenciat en Psicologia & 170 & 1,2 & 0,6 & 0,6 & 30,0 & 30,6 & 12,4 & 17,1 & 7,6 & 100 \\
\hline Llicenciat en Publicitat i Relacions Públiques & 61 & 1,6 & 0,0 & 4,9 & 23,0 & 27,9 & 8,2 & 29,5 & 4,9 & 100 \\
\hline Llicenciat en Sociologia & 74 & 5,4 & 0,0 & 1,4 & 27,0 & 39,2 & 2,7 & 16,2 & 8,1 & 100 \\
\hline Llicenciat en Teoria de la Literatura i Literatura & 20 & 0,0 & 0,0 & 5,0 & 20,0 & 40,0 & 5,0 & 25,0 & 5,0 & 100 \\
\hline Llicenciat en Traducció i Interpretació (Alemany) & 11 & 0,0 & 0,0 & 0,0 & 27,3 & 27,3 & 9,1 & 27,3 & 9,1 & 100 \\
\hline Llicenciat en Traducció i Interpretació (Anglès) & 39 & 0,0 & 0,0 & 0,0 & 23,1 & 35,9 & 7,7 & 23,1 & 10,3 & 100 \\
\hline Llicenciat en Traducció i Interpretació (Francès) & 10 & 10,0 & 0,0 & 0,0 & 10,0 & 30,0 & 20,0 & 20,0 & 10,0 & 100 \\
\hline Llicenciat en Veterinària & 42 & 0,0 & 0,0 & 0,0 & 2,4 & 45,2 & 14,3 & 19,0 & 19,0 & 100 \\
\hline Llicenciatura de Ciències i Tècniques & 8 & 0,0 & 0,0 & 0,0 & 25,0 & 25,0 & 12,5 & 37,5 & 0,0 & 100 \\
\hline Llicenciatura en Administració i Direcció & 343 & 0,6 & 0,0 & 0,9 & 27,7 & 35,3 & 9,9 & 20,1 & 5,5 & 100 \\
\hline Llicenciatura en Biologia & 121 & 3,3 & 0,0 & 0,0 & 17,4 & 33,9 & 5,0 & 23,1 & 17,4 & 100 \\
\hline Llicenciatura en Ciència i Tecnologia d'Aliments & 64 & 0,0 & 1,6 & 1,6 & 17,2 & 37,5 & 6,3 & 28,1 & 7,8 & 100 \\
\hline Llicenciatura en Ciències Actuarials i Financeres & 26 & 0,0 & 0,0 & 0,0 & 19,2 & 34,6 & 11,5 & 11,5 & 23,1 & 100 \\
\hline Llicenciatura en Ciències del Treball & 98 & 5,1 & 2,0 & 0,0 & 34,7 & 33,7 & 11,2 & 10,2 & 3,1 & 100 \\
\hline Llicenciatura en Ciències Polítiques i de & 95 & 3,2 & 0,0 & 3,2 & 22,1 & 35,8 & 7,4 & 16,8 & 11,6 & 100 \\
\hline Llicenciatura en Comunicació Audiovisual & 93 & 3,2 & 1,1 & 3,2 & 28,0 & 32,3 & 5,4 & 16,1 & 10,8 & 100 \\
\hline Llicenciatura en Dret & 305 & 0,7 & 0,3 & 0,7 & 23,3 & 33,1 & 9,2 & 20,7 & 12,1 & 100 \\
\hline Llicenciatura en Economia & 224 & 0,4 & 0,0 & 1,8 & 23,7 & 39,7 & 5,4 & 22,3 & 6,7 & 100 \\
\hline Llicenciatura en Filologia Anglesa & 82 & 1,2 & 0,0 & 1,2 & 26,8 & 42,7 & 12,2 & 12,2 & 3,7 & 100 \\
\hline Llicenciatura en Filologia Catalana & 23 & 0,0 & 0,0 & 0,0 & 4,3 & 43,5 & 30,4 & 17,4 & 4,3 & 100 \\
\hline Llicenciatura en Filologia Clàssica & 6 & 0,0 & 0,0 & 0,0 & 0,0 & 50,0 & 0,0 & 16,7 & 33,3 & 100 \\
\hline Llicenciatura en Filologia Francesa & 10 & 0,0 & 0,0 & 10,0 & 20,0 & 40,0 & 20,0 & 0,0 & 10,0 & 100 \\
\hline Llicenciatura en Filologia Hispànica & 49 & 6,1 & 0,0 & 0,0 & 22,4 & 40,8 & 12,2 & 14,3 & 4,1 & 100 \\
\hline Llicenciatura en Filologia Italiana & 2 & 0,0 & 0,0 & 0,0 & 50,0 & 50,0 & 0,0 & 0,0 & 0,0 & 100 \\
\hline Llicenciatura en Filosofia & 41 & 14,6 & 0,0 & 2,4 & 22,0 & 24,4 & 19,5 & 17,1 & 0,0 & 100 \\
\hline Llicenciatura en Geografia & 50 & 10,0 & 0,0 & 0,0 & 32,0 & 26,0 & 6,0 & 20,0 & 6,0 & 100 \\
\hline Llicenciatura en Història & 101 & 10,9 & 0,0 & 1,0 & 40,6 & 25,7 & 4,0 & 10,9 & 6,9 & 100 \\
\hline Llicenciatura en Historia de l'Art & 75 & 6,7 & 1,3 & 5,3 & 37,3 & 22,7 & 1,3 & 21,3 & 4,0 & 100 \\
\hline Llicenciatura en Història i Ciències de la Música & 13 & 0,0 & 0,0 & 0,0 & 30,8 & 30,8 & 15,4 & 7,7 & 15,4 & 100 \\
\hline Llicenciatura en Humanitats & 51 & 2,0 & 0,0 & 2,0 & 27,5 & 33,3 & 2,0 & 17,6 & 15,7 & 100 \\
\hline Llicenciatura en Màquines Navals & 3 & 0,0 & 0,0 & 0,0 & 0,0 & 0,0 & 0,0 & 100,0 & 0,0 & 100 \\
\hline Llicenciatura en Nàutica i Transport Marítim & 3 & 0,0 & 0,0 & 0,0 & 0,0 & 33,3 & 0,0 & 66,7 & 0,0 & 100 \\
\hline Llicenciatura en Periodisme & 116 & 2,6 & 0,9 & 0,9 & 17,2 & 34,5 & 8,6 & 24,1 & 11,2 & 100 \\
\hline Llicenciatura en Psicopedagogia & 97 & 1,0 & 0,0 & 0,0 & 14,4 & 43,3 & 18,6 & 12,4 & 10,3 & 100 \\
\hline Llicenciatura en Química & 129 & 0,8 & 0,0 & 0,8 & 28,7 & 32,6 & 15,5 & 13,2 & 8,5 & 100 \\
\hline Llicenciatura en Traducció i Interpretació & 56 & 1,8 & 0,0 & 3,6 & 33,9 & 32,1 & 3,6 & 12,5 & 12,5 & 100 \\
\hline Llicenciatura Estudis d'Asia Oriental & 6 & 16,7 & 0,0 & 16,7 & 0,0 & 50,0 & 0,0 & 16,7 & 0,0 & 100 \\
\hline Llicenciatura Filologia Romànica & 8 & 0,0 & 0,0 & 0,0 & 12,5 & 37,5 & 12,5 & 25,0 & 12,5 & 100 \\
\hline Mestre (Educació Especial) & 126 & 0,0 & 0,0 & 0,0 & 7,1 & 54,0 & 13,5 & 16,7 & 8,7 & 100 \\
\hline Mestre (Educació Física) & 160 & 1,3 & 0,0 & 0,0 & 9,4 & 48,8 & 13,1 & 16,9 & 10,6 & 100 \\
\hline Mestre (Educació Infantil) & 241 & 0,4 & 0,0 & 0,0 & 7,9 & 44,0 & 22,8 & 16,2 & 8,7 & 100 \\
\hline Mestre (Educació Musical) & 100 & 0,0 & 0,0 & 2,0 & 6,0 & 38,0 & 21,0 & 22,0 & 11,0 & 100 \\
\hline Mestre (Educació Primària) & 185 & 0,5 & 0,0 & 0,0 & 6,5 & 46,5 & 17,3 & 21,6 & 7,6 & 100 \\
\hline Mestre (Llengua Estrangera) & 124 & 0,0 & 0,0 & 0,0 & 5,6 & 35,5 & 21,8 & 25,0 & 12,1 & 100 \\
\hline Nutrició Humana i Dietètica & 21 & 0,0 & 0,0 & 0,0 & 28,6 & 38,1 & 14,3 & 14,3 & 4,8 & 100 \\
\hline Odontologia & 18 & 0,0 & 0,0 & 0,0 & 0,0 & 44,4 & 16,7 & 33,3 & 5,6 & 100 \\
\hline Podologia & 24 & 0,0 & 0,0 & 0,0 & 8,3 & 33,3 & 12,5 & 33,3 & 12,5 & 100 \\
\hline Total & 8391 & 1,5 & 0,3 & 1,0 & 24,0 & 36,3 & 10,4 & 17,9 & 8,6 & 100 \\
\hline
\end{tabular}

Fuente: elaboración propia sobre la base de AQU (2011) 
